Os desafios do ensino-aprendizagem de variáveis aleatórias no ensino

fundamental

Diana Simões Ferreira

\author{
INSTITUTO DE MATEMÁTICA E ESTATÍSTICA \\ DA \\ UNIVERSIDADE DE SÃO PAULO \\ PARA \\ OBTENÇÃO DO TÍTULO \\ DE \\ MESTRE EM ENSINO DE MATEMÁTICA
}

Programa: Mestrado Profissional em Ensino de Matemática

Orientadora: Prof ${ }^{\underline{a}}$ Dra. Viviana Giampaoli

Coorientadora: Prof ${ }^{a}$ Dra. Elisete da Conceição Quintaneiro Aubin

São Paulo, dezembro de 2019 
Os desafios do ensino-aprendizagem de variáveis aleatórias no ensino fundamental

Diana Simões Ferreira

\section{INSTITUTO DE MATEMÁTICA E ESTATÍSTICA DA UNIVERSIDADE DE SÃO PAULO}

São Paulo, dezembro de 2019 


\title{
Os desafios do ensino-aprendizagem de variáveis aleatórias no ensino fundamental
}

\author{
Diana Simões Ferreira
}

\section{INSTITUTO DE MATEMÁTICA E ESTATÍSTICA \\ DA \\ UNIVERSIDADE DE SÃO PAULO}

\begin{abstract}
Esta versão dissertação contém as correções e alterações sugeridas pela Comissão Julgadora durante a defesa realizada em 03/12/2019 e substitui a versão original depositado inicialmente no Instituto de Matemática e Estatística da Universidade de São Paulo
\end{abstract}

Comissão Julgadora:

- Profa. Dra. Viviana Giampaoli (Presidente) - IME-USP

- Profa. Dra. Mauren Porciúncula Moreira da Silva - FURG

- Prof. Dr. Daniel Miranda Machado - UFABC

São Paulo, dezembro de 2019 


\section{Agradecimentos}

A presente dissertação de mestrado não poderia chegar a bom porto sem o precioso apoio da minha orientadora, Professora Doutora Viviana Giampaoli, e Coorientadora Professora Doutora Elisete da Conceição Quintaneiro Aubin por toda a paciência que tiveram comigo ao longo deste trabalho. Muito obrigada por me terem corrigido quando necessário, sem nunca me desmotivar.

Agradeço imensamente as professoras Dra. Iole de Freitas Druck e Dra. Ligia Carla Pinto Henriques Jorge Rodrigues por terem aceitado participar da minha banca de qualificação, seus apontamentos, análises e sugestões foram essenciais para a melhoria e completude deste trabalho.

O professor Dr. Marcos Nascimento Magalhães que teceu comentários e sugestões riquíssimas durante minha apresentação no $5^{\circ}$ Encontro do MPEM.

Minha gratidão ao Instituto de Matemática e Estatística por acreditar e incentivar seus alunos, em especial aos professores do programa Mestrado Profissional em Ensino de Matemática.

Agradecimentos especiais ao professor e cartunista Dr. Heliodoro Teixeira Bastos Filho que gentilmente autorizou a divulgação de uma de suas charges em nosso trabalho para ilustrar um dos exemplos.

Agradeço ainda a professora Dra. Mauren Porciúncula Moreira da Silva e o professor Dr. Daniel Miranda Machado por terem aceitado participar da Comissão Julgadora da Banca de Defesa de Mestrado e pelas sugestões riquíssimas, as quais foram incorporadas na versão final deste trabalho.

Por fim, agradeço à minha mãe e amigos pelo apoio incondicional que me deram. 


\section{RESUMO}

A presente dissertação tem como objetivo propor o ensino de estatística na educação básica por meio de um currículo em espiral. Inicialmente é apresentado um panorama do ensino de estatística e em qual contexto esta ciência foi incluída na educação básica. O principal referencial teórico é Bruner (1973), que propõe um currículo em espiral. Utilizamos, também, como referências teóricas, os trabalhos de Batanero (2000) e Heitele (1975), em que propõe dez ideias fundamentais para o ensino de estatística, sendo variável aleatória uma delas, e o trabalho de Ruiz; Huerta; Batanero (2011). Apresentamos, ainda, três exemplos voltados para os anos finais do ensino fundamental, que abordam os conceitos básicos de probabilidade e, principalmente, de variáveis aleatórias e, em seguida, fazemos a sistematização dos conceitos, relacionando-os com os exemplos apresentados. Por fim, foi realizada uma breve análise da abordagem adotada em dois livros utilizados no curso de Licenciatura em Matemática no Instituto de Matemática e Estatística da USP.

Palavras chaves: variáveis aleatórias; estatística; educação básica; currículo em espiral. 


\begin{abstract}
The present work aims to propose the teaching of basic statistics through a spiral curriculum. Initially an overview of the teaching of statistics is presented and in what context this science was included in basic education. The main theoretical reference of this work is Bruner (1973), who makes a spiral curriculum. Also uses as theoretical references the works of Batanero (2000) and Heitele (1975), which publishes ten fundamental ideas for teaching statistics and one of them is random variable and the work of Ruiz; Huerta; Batanero (2011). In this paper, we present three examples for the final years of elementary school, which deal with the basic concepts of probability and mainly random variables, and then we use the systematization of concepts, always making the relationship with the examples cited. Finally, a brief analysis of the approach adopted in two books used in the undergraduate mathematics course of the USP Institute of Mathematics and Statistics was performed.
\end{abstract}

Keywords: random variables; statistic; basic education; spiral curriculum 


\section{SUMÁRIO}

1. Apresentação …........................................................ 08

2. Metodologia ….......................................................... 17

3. Variável aleatória: uma abordagem por meio de

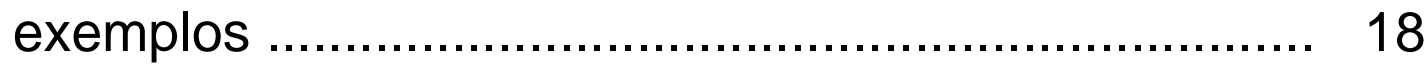

3.1. Apresentação .............................................. 21

3.1.1. Exemplo 1: dia e mês de nascimento ........ 22

3.1.2. Exemplo 2: Letras dos nomes .................. 27

3.1.3. Exemplo 3: Máquina caseira de Galton...... 33

4. Formalizando o Conceito com aplicações ................. 37

4.1. Sistematizando .............................................. 37

4.2. A abordagem de variáveis aleatórias na literatura brasileira para o ensino superior ........ 46

Considerações Finais .................................................. 51

Referências bibliográficas .......................................... 53 


\section{Apresentação}

O desenvolvimento frenético da tecnologia e o consequente acesso aos meios de comunicações na sociedade atual contribuíram para que se decidisse pela incorporação do ensino de estatística no ensino básico. A estatística faz parte do cotidiano de muitos alunos, sendo necessária a percepção e o entendimento mínimo de seus temas por parte dos mesmos, além disso, trata-se de um assunto que engloba diversos campos e saberes profissionais, não exclusivamente no campo das ciências exatas, mas também no que tange a outros campos da ciência, como as ciências sociais e econômicas. Apresentando como campo da matemática, há características que the são próprias, não somente pelos seus processos, como destacado em Oliveira (2012), senão, principalmente, pelas noções de variabilidade e aleatoriedade que the são exclusivas.

A estatística é a parte da matemática aplicada que apresenta processos próprios para coletar, apresentar e interpretar adequadamente conjuntos de dados, sejam eles numéricos ou não. (OLIVEIRA, 2012, p. 1)

A importância da estatística na formação do cidadão é crescente, na medida em que este fica exposto a informações estatísticas veiculadas em jornais, revistas, internet e outras mídias. Tais informações influenciam em tomadas de decisões que, muitas vezes, pela ausência ou pouco conhecimento estatístico torna o cidadão vulnerável a interpretações errôneas.

As informações vêm vestidas em complexas tabelas e gráficos que medem, geralmente com aridez, do décimo ao centésimo de um ponto decimal, o empacotamento das conclusões de uma pesquisa faz com que elas pareçam ainda mais intimidadoras do que realmente são. As únicas pessoas que podem analisar as pesquisas são aquelas que as fazem. Isto praticamente garante uma recepção acrítica da imprensa e do público. (CARZOLA, 2002)

Durante muito tempo, o estudo de estatística ficou restrito a universidades, centros de pesquisas e empresas, pois geravam grandes volumes de informação e só podiam ser processados em computadores de grande porte. No Brasil, a estatística tem seu desenvolvimento associado à história do Instituto Brasileiro de Geografia e Estatística - IBGE, cujas origens se remetem ainda ao Império, apesar de sua criação ter sido em 1936, pois antes já haviam sido realizados diversos censos. O progresso da informática e popularização de microcomputadores pessoais e de softwares amigáveis facilitaram o uso de ferramentas estatísticas por qualquer usuário. 
O ensino de estatística tem início logo nos Anos Iniciais onde são introduzidos conceitos básicos da análise exploratória de dados e da teoria de probabilidades, porém somente no Ensino Médio são aprofundados. Até a implantação dos Parâmetros Curriculares Nacionais - PCNs (Brasil, 1998) o ensino de Estatística no nível fundamental e médio era muito restrito. Hoje esse quadro mudou pelo destaque especial que é dado pela Base Nacional Comum Curricular - BNCC (Brasil, 2017).

No caso do Ensino Fundamental - para o qual este trabalho se restringe - os conteúdos de Estatística, Probabilidade e Combinatória, de acordo com os PCNs, estão enunciados no bloco tratamento da informação, dentro do programa de Matemática. A finalidade do ensino de Estatística era fazer com que o aluno construísse procedimentos para coletar, organizar, comunicar dados, utilizando tabelas, gráficos e representações que aparecem frequentemente no cotidiano, bem como o cálculo de algumas medidas tais como a média, mediana e moda, a fim de poder estabelecer relações entre acontecimentos, fazer previsões, observar a frequência com que ocorre um acontecimento. O bloco tratamento da informação contribuía para relacionar a Matemática a outras áreas do conhecimento e com os Temas Transversais.

\begin{abstract}
A interação do ensino de Matemática com os Temas Transversais é uma questão bastante nova. Centrado em si mesmo, limitando-se à exploração de conteúdos meramente acadêmicos, de forma isolada, sem qualquer conexão entre seus próprios campos ou com outras áreas de conhecimento, o ensino dessa disciplina pouco tem contribuído para a formação integral do aluno, com vistas à conquista da cidadania. (BRASIL, 1997)
\end{abstract}

Com a aprovação da BNCC, Probabilidade e Estatística ganhou, dentro da Matemática, o status de uma unidade temática, possibilitando a aprendizagem e desenvolvimento desde as séries iniciais.

\begin{abstract}
A incerteza e o tratamento de dados são estudados na unidade temática Probabilidade e Estatística. Ela propõe a abordagem de conceitos, fatos e procedimentos presentes em muitas situações- -problema da vida cotidiana, das ciências e da tecnologia. Assim, todos os cidadãos precisam desenvolver habilidades para coletar, organizar, representar, interpretar e analisar dados em uma variedade de contextos, de maneira a fazer julgamentos bem fundamentados e tomar as decisões adequadas. Isso inclui raciocinar e utilizar conceitos, representações e índices estatísticos para descrever, explicar e predizer fenômenos. (BRASIL, 2017)
\end{abstract}

Além disso, a BNCC propõe que, no Ensino Fundamental - Anos Iniciais, o ensino das noções de probabilidade promova a compreensão de que nem todos os 
fenômenos sejam determinísticos, desenvolvendo noções de aleatoriedade, possibilitando a compreensão de que há eventos certos, eventos impossíveis e eventos prováveis. Em relação à estatística, a expectativa é que os alunos consigam planejar e construir relatórios de pesquisas com estatísticas descritivas, incluindo medidas de tendência central e construção de tabelas e diversos tipos de gráfico. Já no Ensino Fundamental - Anos Finais, o estudo deve ser ampliado e aprofundado, por meio de atividades nas quais os alunos façam experimentos aleatórios e simulações para confrontar os resultados obtidos com a probabilidade teórica probabilidade frequentista. A progressão dos conhecimentos se faz pelo aprimoramento da capacidade de enumeração dos elementos do espaço amostral, que está associada, também, aos problemas de contagem ou de combinatória, o qual, se não bem trabalhado em sala de aula, pode criar barreiras ou falsas intuições. Com relação à estatística, conforme mencionado acima, os primeiros passos envolvem o trabalho com a coleta e a organização de dados de uma pesquisa de interesse dos alunos, e a partir daí, que eles saibam planejar e construir relatórios de pesquisas apresentando análises descritivas, que incluam medidas de tendência central, diferentes tabelas e gráficos. Esse planejamento inclui a definição de questões relevantes e da identificação da população a ser pesquisada, a decisão sobre a necessidade ou não de usar amostra e, quando for o caso, a seleção de seus elementos por meio de uma adequada técnica de amostragem.

Nos documentos internacionais, é cada vez mais frequente apontar a necessidade de que os alunos adquiram, ao longo da sua formação, letramento e pensamento estatístico consistentes. O Guidelines for Assessment and Instruction in Statistics Education - GAISE é um desses documentos internacionais, que apontam a necessidade de identificar, planejar e entender sobre a necessidade ou não do uso de amostra, bem como estudar o "comportamento de uma amostra aleatória".

\footnotetext{
Um cidadão informado pelas pesquisas deve entender que os resultados foram determinados a partir de uma mostra da população em estudo, que a confiabilidade dos resultados depende de como a amostra foi selecionada,e que os resultados estão sujeitos a erros de amostragem. Os cidadãos, estatisticamente alfabetizados, devem entender o comportamento de amostras "aleatórias" e estar em condições de interpretar uma "margem de erro de amostragem". (GAISE, 2005).
}

De acordo com Novaes (2011, p.28) o GAISE foi um documento aprovado pela ASA (American Statistical Association) e teve como objetivo complementar as recomendações dos princípios e normas, proposto pelo NCTM (National Council of 
Teachers of Mathematics) em 2000. O NCTM é um conselho de professores de matemática que atua nos Estados Unidos e Canadá e conta com a publicação de cinco revistas e ainda realizam conferências anuais voltadas para educação matemática.

O fato de Estatística estar presente em diversas outras áreas e por ser um campo relativamente recente da matemática provoca uma certa insegurança dos docentes em fazer a abordagem da Estatística, diferentemente de uma mera instrumentalização de fórmulas e cálculos numéricos, desprovida de uma interpretação adequada dos resultados que permita ter um caráter formativo. Assim, o ensino da Estatística não pode se resumir ao tratamento usual, que consiste em demonstrar teoremas e realizar cálculos; ele vai além, por exemplo, com a descrição de experimentos, análises dos dados provenientes de pesquisas, fazendo uma conexão da estatística com o processo que gerou as hipóteses ou questionamentos.

O ensino da matemática tem como tradição a exatidão, o determinismo e o cálculo, opondo-se à exploração de situações que envolvam aproximação, aleatoriedade e estimação, as quais podem limitar a visão matemática que o aluno poderá desenvolver, dificultando suas possibilidades de estabelecimento de estratégias para a resolução. (LOPES, 2008).

Em documentos internacionais, como os apresentados pelo NCTM e o já citado GAISE, o ensino da Estatística é abordado por meio de explorações de situações e análises. Os Principles and Standards do NCTM são um documento não oficial, no sentido de que não tem força de lei nos EUA, porém, é uma forte referência, não só para nosso trabalho, como para professores que irão abordar a área de estatística, pois é recheado de exemplos e justificativas. O NCTM foi, inclusive também, uma forte referência para a elaboração dos Parâmetros Curriculares Nacionais como pode-se ver no trecho abaixo retirado do PCN.

Em 1980, o National Council of Teachers of Mathematics, NCTM, dos Estados Unidos, apresentou recomendações para o ensino de Matemática no documento Agenda para Ação 2. Nele, a resolução de problemas era destacada como o foco do ensino da Matemática nos anos 80. Também a compreensão da relevância de aspectos sociais, antropológicos, linguísticos, além dos cognitivos, na aprendizagem da Matemática, imprimiu novos rumos às discussões curriculares. (...) incluindo já no ensino fundamental, por exemplo, elementos de estatística, probabilidade e combinatória para atender à demanda social que indica a necessidade de abordar esses assuntos. (BRASIL, 1998)

No geral, nos livros didáticos brasileiros a estatística e probabilidade são quase sempre apresentadas como relacionadas a jogos de azar e não se baseiam 
em dados de situações cotidianas, em que os próprios alunos poderiam estudar segundo seus próprios interesses, o que torna o ensino de estatística deficiente.

É necessária a mobilização de uma série de conhecimentos de ordem
conceitual, procedimental e atitudinal. Saber lidar com tais processos
implica uma real preparação do professor, o qual, muitas vezes, não teve
acesso a esses conhecimentos no seu processo de formação inicial ou
continuada. Assim, ele necessita de um maior apoio em relação às
questões conceituais, pedagógicas e didáticas, para poder propor situações
que efetivem a construção do conhecimento estatístico. (GUIMARÃES, et
al, 2009)

O NCTM sugere que ao ensinar estatística, os estudos realizados sejam com os próprios alunos, de seus interesses cotidianos. Além disso, este documento, assim como o já citado GAISE, apresenta alguns exemplos de experiências, que podem ser utilizadas na exploração e compreensão de determinados fenômenos e que fogem do contexto de jogos de azar e de dados, estando mais próximos dos alunos.

Neste trabalho, fazemos a abordagem do ensino de estatística, tendo como eixo central a ideia de variável aleatória, que segundo Heitele (1975), uma ideia estocástica fundamental. Essas ideias são analisadas por Batanero (2004), que indica que sua importância se deve aos seguintes pontos:

- São conceitos que desempenharam um papel importante no desenvolvimento da Probabilidade como uma teoria matemática; espera-se, então, que eles também contribuam para a compreensão da probabilidade pelos alunos.

- Eles são contra-intuitivos e não são aprendidos espontaneamente, a menos que sejam ensinados. Eles podem ser ensinados de acordo com o nível apropriado da escola.

- Aparecem em muitas situações cotidianas, portanto, eles podem ser aplicados com frequência.

Para Batanero (2004), as ideias fundamentais estatísticas podem ser apresentadas à criança em cada estágio de seu desenvolvimento, fornecendo-lhes modelos explicativos dos fenômenos do acaso que eles observam, que sejam suficientes nesse estágio.

A importância da variável aleatória foi destacada por Heitele (1975) quando, baseando-se em um enfoque epistemológico-pragmático, incluiu variável aleatória em sua lista de dez ideias fundamentais no ensino de probabilidade e estatística, 
que os estudantes desenvolvem desde os níveis educativos básicos até o nível superior. Segundo este autor, uma ideia fundamental proporciona modelos explicativos em cada etapa do desenvolvimento do conceito, em conjunto com o avanço da educação do indivíduo. Heitele (1975) baseou-se na concepção de ideia fundamental proposta por Bruner (1960). Para Bruner, as ideias fundamentais são importantes em uma perspectiva curricular, pois permite definir quais são os tópicos que se estudam em cada nível escolar e com qual profundidade. Além disso, permite criar elos com outros ramos da matemática, gerando uma rede de conhecimentos que não só propicia a aprendizagem formal dos conceitos, mas, também, educa a percepção e desenvolve conexões significantes com a realidade. De acordo com Ruiz (2006)

Segundo Heitele, uma ideia fundamental é aquela que se possa ensinar de maneira proveitosa em qualquer nível escolar, com nível de aprendizagem bem definido. Sua lógica está de acordo com o currículo em espiral, em que, em cada etapa, desenvolvem-se modelos explicativos sobre uma ideia fundamental, que diferem nos níveis de conhecimento em sua forma linguística e em níveis de profundidades, mas não em sua estrutura. Ruiz (2013) afirma em sua tese de doutorado que um dos preceitos básicos do currículo em espiral é que um aluno possa ser capaz de aprender qualquer tema em certo nível de profundidade e, consequentemente, todos os tópicos podem ser apresentados em uma idade precoce, mas não se pode ser fatigante a nenhuma idade, mas podem ser retomados para incrementar sua profundidade.

O princípio básico do currículo em espiral é que uma criança é capaz de aprender seriamente qualquer matéria em um determinado nível e que, portanto, todos os tópicos podem ser introduzidos em tenra idade, mas que não podem ser exaustivos em nenhuma idade, mas que eles só podem ser retomados para aumentar sua profundidade. Heitele fornece como exemplo desse processo curricular o desenvolvimento cognitivo da ideia de variável aleatória. (RUIZ, 2013, tradução nossa)

Variável aleatória não é um conceito simples, visto que por ele afluem muitos outros conceitos matemáticos, estatísticos e probabilísticos provenientes dos níveis básicos e superior e ainda está relacionado com conceitos abstratos próprios do ensino superior, como o de funções inversas e álgebras de conjuntos. 
Heitele (1975) coloca como exemplo de currículo em espiral justamente o de variável aleatória. A primeira apresentação de um modelo explicativo intuitivo é onde o aluno observa repetições de um fenômeno e interpreta o que ocorre com maior frequência, por meio de atividades nas quais não se envolve uma instrução formal nem analítica.

Segundo Bruner (1973), é possível ensinar qualquer assunto, de uma maneira intelectualmente honesta, a qualquer criança, em qualquer estágio de desenvolvimento, desde que sejam levadas em conta as diversas etapas do amadurecimento intelectual do aluno. Neste processo, o papel do educador é fundamental para facilitar e ordenar os processos de representação por parte do aluno, estimulando a que este explore novas alternativas. Pode-se pensar que há três fatores envolvidos no processo de exploração de alternativas: a ativação (a qual dá início ao processo, por exemplo, a curiosidade), manutenção e direção. Bruner ainda afirma que um currículo, à medida que se desenvolve, deve voltar repetidas vezes a essas ideias básicas, elaborando e reelaborando-as, até que o aluno tenha captado inteiramente a sua completa formulação sistemática. Cada conteúdo é abordado, a princípio, em sua essência, com suas características mais importantes para, finalmente, ser explorado em outros contextos, na maioria deles como ferramenta para resolver parte de uma situação-problema mais complexa, servindo como uma das bases que irão sustentar um novo conceito.

Vale observar que na própria BNCC, mesmo que de forma implícita, é sugerido o uso de um currículo em espiral quando nas orientações menciona-se que as habilidades devem, a cada ano, ter progressão e complexidade. O texto chega a exemplificar que os problemas de contagem, inicialmente, devem se restringir a situações em que o aluno seja capaz de enumerar todos os casos possíveis e posteriormente fazer o uso dos princípios aditivos e multiplicativos.

$\mathrm{Na}$ definição das habilidades, a progressão ano a ano se baseia na compreensão e utilização de novas ferramentas e também na complexidade das situações-problema propostas, cuja resolução exige a execução de mais etapas ou noções de unidades temáticas distintas. Os problemas de contagem, por exemplo, devem, inicialmente, estar restritos àquelas cujas soluções podem ser obtidas pela descrição de todos os casos possíveis, mediante a utilização de esquemas ou diagramas, e, posteriormente, àqueles cuja resolução depende da aplicação dos princípios multiplicativo e aditivo e do princípio da casa dos pombos. Outro exemplo é o da resolução de problemas envolvendo as operações fundamentais, utilizando ou não a linguagem algébrica. (BRASIL, 2017) 
É importante que a cada retomada a determinado conteúdo, as atividades propostas pelo professor proporcionem situações que estimulem o aluno a refletir, conjecturar, inferir, estimar, demonstrar, provar, relacionar, analisar, estabelecendo novas relações e não apenas calcular e efetuar. $O(a)$ professor(a) terá a responsabilidade da planificação, de como o material será apresentado, considerando a sequência dos mesmos, tendo ainda que estar atento à manutenção da motivação e predisposição dos alunos para resolver os problemas. Assim, a maior preocupação está focada em como os conteúdos serão apresentados ao aluno e ao tipo de metodologia que o(a) professor(a) irá utilizar, pois por meio do pensamento intuitivo o aluno poderá chegar a soluções que não conseguiria usando apenas o pensamento analítico. No entanto, uma vez conseguido que o(a) aluno(a) chegue à solução pelo pensamento intuitivo, de maneira gradual e de acordo com as possibilidades, a solução deve ser verificada por métodos analíticos.

\begin{abstract}
Através do pensamento intuitivo, o indivíduo poderá, muitas vezes, chegar a soluções para problemas que não conseguiria alcançar de modo algum ou, quando muito, só mais lentamente, através do pensamento analítico. Uma vez conseguidas por métodos intuitivos, essas soluções deverão, se possível, ser verificadas por métodos analíticos, sendo ao mesmo tempo respeitadas como hipóteses válidas para tal verificação. Realmente, o pensador intuitivo pode até mesmo inventar ou descobrir problemas que o analista não descobriria. Poderá ser, contudo, o analista, quem irá dar aos problemas o formalismo conveniente. (Bruner, 1973, p. 54)
\end{abstract}

Enfatizamos que, segundo Bruner (1973), os pensamentos intuitivo e analítico se completam. Ele não aponta nenhuma ordem como começar do intuitivo e chegar ao analítico, mas sim uma harmonia entre ambos. Bruner afirma que a linguagem não é apenas o meio de comunicação e sim um instrumento que possibilita organizar e ordenar o meio, destacando assim a importância da linguagem adequada no processo de ensino. Dois esquemas que resumem o modelo do currículo em espiral de maneira simplificada são mostrados na Figura 1.

Ruiz (2013) apresenta, em seu trabalho, três etapas diferentes de como pode ser feito a abordagem de variável aleatória segundo Heitele. Em um primeiro estágio, ele propõe a noção de esperança vinculada à variável de interesse que a criança detectar, a partir da observação de valores, e qual é o critério que se estabeleceria para tomar uma decisão sobre qual valor é mais conveniente apostar. Ainda que neste nível o modelo é meramente intuitivo, estabelece-se préconhecimentos analíticos posteriores, como o de espaço amostral, probabilidade, 
frequência e esperança matemática além de uma pré-ideia do conceito de variável aleatória por meio da variável de interesse.

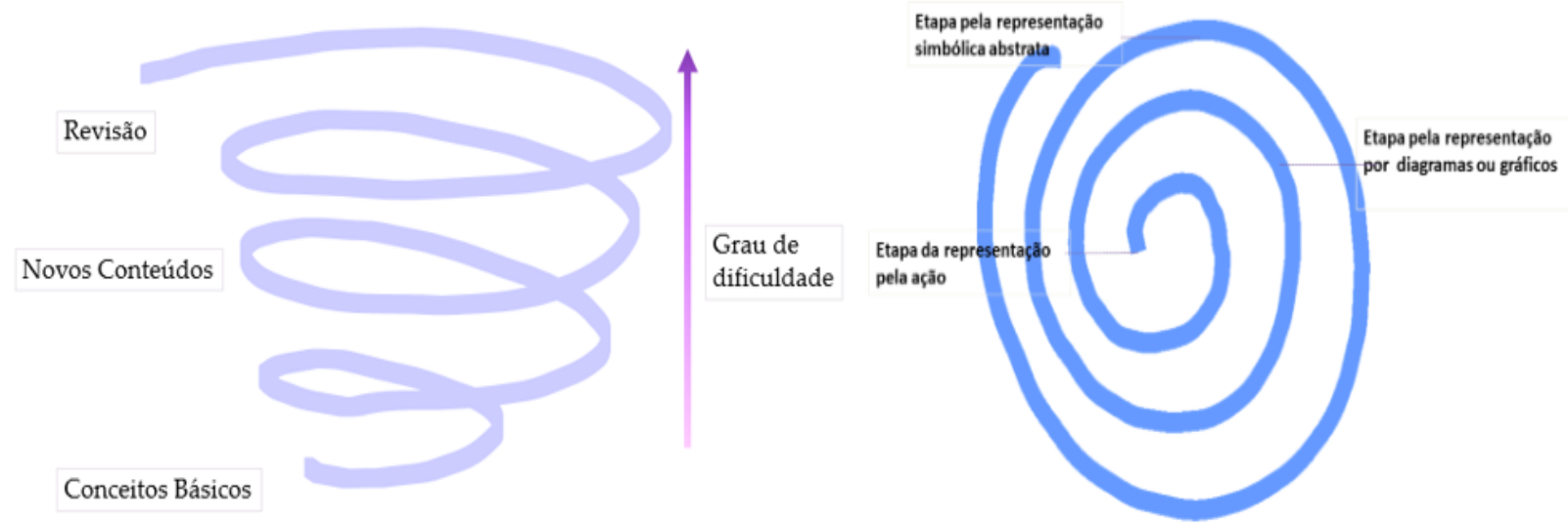

Figura 1. Esquema representando currículo em espiral

Em um estágio intermediário, pode ser enfatizado um modelo mais quantitativo, em que não somente se identifique, mas, também, se enumerem os eventos possíveis e identifiquem os favoráveis. Dessa forma, retoma-se a variável estatística como uma pré-ideia de variável aleatória e se pré-estabelece a distribuição da probabilidade e esperança matemática, mas já se manipula conhecimento analítico, como o conceito de probabilidade clássica.

Um modelo mais elaborado, segundo Ruiz (2013), permitiria o reconhecimento e interpretação da variável aleatória, facilitando a análise da situação de uma maneira mais abrangente e a identificação dos parâmetros que podem definir o comportamento de um fenômeno. Nesta etapa, o conhecimento explorado seria mais analítico.

No capítulo seguinte exibiremos exemplos de atividades envolvendo variáveis aleatórias e, em cada um deles, serão discutidos conceitos como evento, espaço amostral, probabilidade, tanto de modo intuitivo como, posteriormente, cada definição será formalizada. O capítulo seguinte abordará também, segundo os preceitos de Bruner (1973), por meio de uma apresentação em espiral, o conceito de variável aleatória desde uma abordagem mais superficial voltada para aplicação na educação básica, como, também, contará com uma seção que pode contribuir para a formação docente e enriquecimento do conhecimento do leitor. 


\section{Metodologia}

Este trabalho foi desenvolvido a partir de uma pesquisa bibliográfica, por meio de fontes virtuais de sites acadêmicos confiáveis, documentos oficiais do MEC, documentos internacionais sobre educação estatística ou educação matemática e buscas no Google Acadêmico. Foi realizado um trabalho investigativo minucioso a pesquisas que abordavam o ensino de estatística no ensino básico por meio de variáveis aleatórias. Utilizou-se como principal referência para esta metodologia Severino (2007) e PIZZANI (2012).

A pesquisa bibliográfica é aquela que se realiza a partir do registro disponível, decorrentes de pesquisas anteriores em documentos impressos, como livros, artigos, teses etc. Utiliza-se de dados ou de categorias teóricas já trabalhados por outros pesquisadores e devidamente registrados. Os textos tornam-se fontes dos temas a serem pesquisados. O pesquisador trabalha a partir das contribuições dos autores dos estudos analíticos constantes dos textos. (SEVERINO, 2007, p. 122).

Inicialmente delimitou-se o tema, uma vez que variável aleatória era um tema muito amplo, nossa investigação restringiu-se ao ensino de variáveis aleatórias na educação básica. A busca de artigos, teses e dissertações foi feita através do banco de dissertações da CAPES, Scielo, Google Acadêmico, Ibict. A busca foi realizada pelas palavras chaves: variáveis aleatórias, estatística, currículo em espiral, random variables, statistic, basic education, spiral curriculum. Optou-se pela busca de palavras em inglês pois, além de ser um idioma de grande acesso mundial, a literatura acerca de variáveis aleatórias é bastante restrita no idioma português.

O pesquisador deve formular um título para o seu levantamento bibliográfico e identificar os termos que expressem o seu conteúdo, não só no idioma português, como também em outros, principalmente em inglês por ser o idioma de grande acesso mundial. (PIZZANI et al, 2012)

O segundo passo foi realizar um fichamento das citações importantes. Após localizar e organizar as fontes, foi realizado uma leitura sistemática obedecendo uma ordem de prioridade: do mais recente para o mais antigo.

A revisão bibliográfica permitiu um aprendizado sobre variáveis aleatórias e ofereceu subsídios para a redação deste trabalho. 


\section{Variável aleatória: uma abordagem por meio de exemplos}

O objetivo principal deste capítulo é propor uma estratégia pedagógica (3 exemplos) a partir da revisão de literatura. Mostraremos que é possível desenvolver atividades que contemplem o currículo em espiral e que, a partir de ideias intuitivas, é possível chegarmos em pensamentos analíticos, sempre retomando os temas abordados anteriormente, considerando diversas representações em diferentes graus de profundidade.

Estatística entrou oficialmente nos currículos brasileiros no fim da década de 90, com a implantação dos Parâmetros Curriculares Nacionais - PCN - referentes ao Ensino Fundamental (anos iniciais e anos finais) e Ensino Médio, no entanto, sendo parte de um bloco de conteúdo denominado Tratamento da Informação, incluído dentro da componente curricular Matemática. Como foi a primeira vez que Estatística foi oficialmente discutida na proposta curricular brasileira, o objetivo da inserção estava relacionado à formação de cidadãos críticos, já que tais conteúdos estão diretamente ligados à leitura, interpretação e análise e compreensão de informações veiculadas, bem como, à previsão de situações e à tomada de decisões. Como pode-se ler no parágrafo a seguir.

Com relação à Estatística, a finalidade é fazer com que o aluno venha a
construir procedimentos para coletar, organizar, comunicar dados, utilizando
tabelas, gráficos e representações que aparecem frequentemente em seu
dia a dia. Além disso, calcular algumas medidas estatísticas como média,
mediana e moda com o objetivo de fornecer novos elementos para
interpretar dados estatísticos. (BRASIL, 1997)

Segundo Walichinski et al (2014), até a implantação dos PCN's, os livros didáticos raramente apresentavam conteúdos referente a estatística a partir da $5^{\mathrm{a}}$ série ( $6^{\circ}$ ano), fazendo-o, geralmente, a partir da oitava série ( $9^{\circ}$ ano).

No Brasil, percebe-se que essa inclusão ocorreu tardiamente, pois os conteúdos de Estatística, Probabilidade e Combinatória só foram inseridos no currículo em 1997 com a publicação dos Parâmetros Curriculares Nacionais (PCN), para os anos iniciais do Ensino Fundamental, em 1998, com a publicação dos PCN para os anos finais do Ensino Fundamental e, em 1999, com a publicação dos PCN para o Ensino Médio. (WALICHINSKI et al, 2014)

Devido a importância da estatística e ao fato de que esta não se relaciona somente à leitura e interpretação de dados, no fim de 2017 foi aprovada a versão final da Base Nacional Comum Curricular, BNCC, na qual Estatística e Probabilidade apresentam-se como uma das cinco unidades temáticas: números, álgebra, geometria, grandezas e medidas e probabilidade e estatística. A importância da educação estatística é destacada por Lopes (2006), em que se dá ênfase à 
habilidade para realizar análises críticas, não se limitando à leitura de dados ou procedimentos de cálculo.

A educação estatística não apenas auxilia a leitura e a interpretação de dados, mas fornece a habilidade para que uma pessoa possa analisar e relacionar criticamente os dados apresentados, questionando e até mesmo ponderando sua veracidade. (LOPES, 2006).

$\mathrm{Na} \mathrm{BNCC}$, ao se tratar de estatística, espera-se que o aluno desenvolva habilidades que possibilitem a coleta, organização e diferentes formas de representação de dados, além disso, o educando deve ser capaz de analisar e julgar as informações de maneira fundamentada. Um avanço em relação ao PCN é que a BNCC apresenta estatística e probabilidade desde o ensino infantil, enquanto o PCN somente a partir dos anos iniciais do ensino fundamental.

Ela propõe a abordagem de conceitos, fatos e procedimentos presentes em muitas situações-problema da vida cotidiana, das ciências e da tecnologia. Assim, todos os cidadãos precisam desenvolver habilidades para coletar, organizar, representar, interpretar e analisar dados em uma variedade de contextos, de maneira a fazer julgamentos bem fundamentados e tomar as decisões adequadas. Isso inclui raciocinar e utilizar conceitos, representações e índices estatísticos para descrever, explicar e predizer fenômenos. (BRASIL, 2017)

Batanero (2000) sugere que a abordagem da estatística deve ser a partir de situações do dia a dia do aluno ou ao menos relacionadas com seu cotidiano, de modo a promover o significado, a motivação e o interesse dos alunos, o que vai de encontro com o que a BNCC propõe, quando menciona abordagem de situaçõesproblemas da vida cotidiana.

Ao se tratar de probabilidade nos PCN já se mencionava a importância do entendimento da natureza aleatória de alguns fenômenos.

Com relação à probabilidade, a principal finalidade é a de que o aluno compreenda que muitos dos acontecimentos do cotidiano são de natureza aleatória e que se podem identificar possíveis resultados desses acontecimentos e até estimar o grau da possibilidade acerca do resultado de um deles. As noções de acaso e incerteza, que se manifestam intuitivamente, podem ser exploradas na escola, em situações em que o aluno realiza experimentos e observa eventos (em espaços equiprováveis). (BRASIL, 1997)

Desde a educação infantil, com um maior detalhe, a BNCC propõe a discussão do caráter de aleatoriedade, chegando mencionar a análise da ideia de aleatório em situações do cotidiano, tais como classificar resultados de eventos cotidianos aleatórios como "pouco prováveis", "muito prováveis", “improváveis" e "impossíveis". Batanero e Godino (2002) afirmam que o aluno deve observar o 
caráter imprevisível de cada resultado isoladamente num experimento aleatório, percebendo a variabilidade das pequenas amostras.

Baseado nos estudos de Bruner, Heitele (1975) incluiu variáveis aleatórias em sua lista de dez "ideias fundamentais da Estocástica" que devem estar presentes no processo de ensino e aprendizagem da Matemática, são elas:

a) a probabilidade como normalização de nossas crenças;

b) espaço amostral como conjunto de todas as possibilidades;

c) regra de adição de probabilidades;

d) independência e regra do produto;

e) equidistribuição e simetria;

f) análise combinatória;

g) modelos de urnas e simulação;

h) variável aleatória;

i) a lei dos grandes números;

j) amostras.

O assunto variável aleatória é tratado como uma das dez ideias fundamentais no ensino de estatística por Heitele (1975), pois ela proporciona modelos explicativos em várias fases do desenvolvimento. As ideias fundamentais promovem aos alunos uma forma de ensino/aprendizagem que se difere quanto ao nível cognitivo, preservando sua estrutura, porém alterando a linguagem com que é abordada (mais simples ou rebuscada) e o nível de aprofundamento indo e voltando várias vezes sobre o tema.

Para Bruner (1973), "um currículo, à medida que se desenvolve, deve voltar repetidas vezes a essas ideias básicas, elaborando e reelaborando-as, até que o aluno tenha captado inteiramente a sua completa formulação sistemática". Bruner ainda afirma que qualquer assunto pode ser ensinado a uma criança em qualquer estágio de desenvolvimento.

Partimos da hipótese de que qualquer assunto pode ser ensinado com eficiência, de alguma forma intelectualmente honesta, a qualquer criança, em qualquer estágio de desenvolvimento. É uma hipótese arrojada, mas essencial, quando se pensa sobre a natureza de um currículo. (BRUNER, 1973).

Para que um determinado assunto seja ensinado de maneira efetiva, como já foi mencionado no capítulo anterior, Bruner propõe que se inicie por um modelo 
intuitivo para, finalmente, tentar elaborar hipóteses analíticas (que se possível permitam ser verificadas).

Cremos que deveria ser reconhecida a natureza mutuamente complementar dos pensamentos intuitivo e analítico. Através do pensamento intuitivo, o indivíduo poderá, muitas vezes, chegar a soluções para problemas que não conseguiria alcançar de modo algum ou, quando muito, só mais lentamente, através do pensamento analítico. Uma vez conseguidas por métodos intuitivos, essas soluções deverão, se possível, ser verificadas por métodos analíticos, sendo ao mesmo tempo respeitadas como hipóteses válidas para tal verificação. Realmente, o pensador intuitivo pode até mesmo inventar ou descobrir problemas que o analista não descobriria. Poderá ser, contudo, o analista, quem irá dar aos problemas o formalismo conveniente. (BRUNER, 1973)

Sendo assim, poderíamos partir da análise de situações cotidianas de interesse do aluno que envolvam variáveis estatísticas e de forma gradativa promovermos a generalização, até chegarmos a variáveis aleatórias.

Em seu trabalho, Albert e Ruiz (2005) observam que os alunos compreendem a noção de variável aleatória, seu contexto de significado, mas dificilmente associam com o conceito de função, e, consequentemente, têm dificuldades em formalizar o conceito. Neste ponto, a proposta do ensino em espiral de Bruner vem ao encontro deste, pois a formalização está nos últimos estágios da aprendizagem. Albert e Ruiz (2005) ainda mostram que os estudantes têm dificuldades em passar o problema para a linguagem matemática, isso possivelmente porque não enxergam a variável aleatória como um modelo matemático.

Heitele (1975) também sinaliza outros três conceitos fundamentais em relação a variáveis aleatórias: variabilidade, esperança e sua distribuição. O conceito de variabilidade é primordial para a compreensão de variável estatística, enquanto os outros poderão ser abordados segundo o nível de aprofundamento do conceito de variável aleatória.

\subsection{Apresentação}

Refletindo sobre o modelo de currículo em espiral e no que Heitele afirma, decidimos apresentar nessa seção a noção de variável aleatória por meio de três atividades para o Ensino Fundamental 2. Pretendemos retomar as mesmas na seção seguinte para uma melhor compreensão da formalização dos conceitos. 
Para os dois primeiros exemplos, utilizaremos os dados de uma turma fictícia de alunos, da sala $S$, apresentados na Tabela 1, com os primeiros nomes, apresentados em ordem alfabética, e seus correspondentes sobrenomes e suas datas de nascimento.

Tabela 1: Lista de nomes, último sobrenome e data de nascimento de 40 alunos de uma turma fictícia $S$ de $6^{\circ}$ Ano

\begin{tabular}{ll|l|lll}
\hline Primeiro Nome & $\begin{array}{l}\text { Último } \\
\text { Sobrenome }\end{array}$ & $\begin{array}{l}\text { Data de } \\
\text { nascimento }\end{array}$ & Primeiro Nome & $\begin{array}{l}\text { Último } \\
\text { Sobrenome }\end{array}$ & $\begin{array}{l}\text { Data de } \\
\text { nascimento }\end{array}$ \\
\hline 1. ALEXANDRE & SANTOS & $02 / 04 / 2007$ & 21. ISABELA & RIBAS & $09 / 06 / 2007$ \\
\hline 2. ALEXSANDRO & DEGASPERI & $18 / 02 / 2007$ & 22. IZABELLI & SANTOS & $08 / 05 / 2007$ \\
\hline 3. ALICE & RAMALHO & $11 / 12 / 2006$ & 23. JOAO & RAMALHO & $11 / 12 / 2006$ \\
\hline 4. ANA & DANTAS & $30 / 10 / 2005$ & 24. KAMILLY & PEREIRA & 04/10/2006 \\
\hline 5. ANA & MACHADO & $10 / 06 / 2007$ & 25. KAUAN & FERREIRA & $06 / 10 / 2006$ \\
\hline 6. ANTONIO & SANTOS & $14 / 10 / 2006$ & 26. KAUE & GOMES & $06 / 07 / 2006$ \\
\hline 7. ARTHUR & SANTOS & $11 / 07 / 2006$ & 27. KAYLLANE & SANTOS & $12 / 11 / 2006$ \\
\hline 8. BEATRIZ & ROSOLEN & $20 / 02 / 2007$ & 28. LARISSA & SILVA & $13 / 04 / 2007$ \\
\hline 9. BEATRIZ & SIMÕES & $12 / 05 / 2007$ & 29 LEONARDO & SOARES & $16 / 06 / 2007$ \\
\hline 10. BIANCA & FERREIRA & $12 / 05 / 2007$ & 30. LUCAS & FERREIRA & $14 / 05 / 2007$ \\
\hline 11. CLARA & MACEDO & $08 / 06 / 2007$ & 31. LUCAS & SILVA & $24 / 06 / 2007$ \\
\hline 12. EDUARDO & SANTOS & $17 / 11 / 2006$ & 32. LUIZA & AZEVEDO & $31 / 05 / 2006$ \\
\hline 13. EVELYN & AYRES & $22 / 02 / 2007$ & 33. MARIA & SANTOS & $10 / 07 / 2006$ \\
\hline 14. FRANCISCO & BENASSI & $26 / 10 / 2006$ & 34. MICAEL & SILVA & $28 / 11 / 2005$ \\
\hline 15. GABRIEL & FERREIRA & $20 / 07 / 2006$ & 35. MIKAELLA & OLIVEIRA & $14 / 11 / 2006$ \\
\hline 16. GABRIEL & BUENO & $22 / 01 / 2007$ & 36. NICOLAS & SANTOS & $17 / 05 / 2007$ \\
\hline 17. GABRIELA & SANDOVAL & $29 / 01 / 2007$ & 37. RAISSA & SANTOS & $30 / 03 / 2007$ \\
\hline 18. GABRIELLI & ARAGÃO & $14 / 10 / 2006$ & 38. REBECA & VIANNA & $21 / 09 / 2006$ \\
\hline 19. GEOVANNA & SILVA & $13 / 10 / 2006$ & 39. SAMARA & FERREIRA & $27 / 05 / 2006$ \\
\hline 20. IGOR & SILVA & $11 / 04 / 2007$ & 40. TIAGO & SILVA & $29 / 05 / 2007$ \\
\hline & & & & & \\
\hline
\end{tabular}

\subsubsection{Exemplo 1: Dia e mês de nascimento}

Vamos considerar que esta atividade possa ser aplicada durante as aulas de matemática de uma turma de 6ํano, mas o(a) professor(a) terá a liberdade de usála em anos anteriores ou posteriores, segundo as características da turma e os conteúdos de estatística proposto no currículo adotado.

Para realizar esta atividade o(a) professor(a) deverá providenciar um calendário de tamanho grande, de qualquer ano, com 12 meses, para colar no mural 
e duas fichas para cada aluno com o desenho de um bolo (uma para colar no calendário e outra para construir um gráfico), que representará o dia e o mês da data de aniversário.

$\mathrm{O}$ (a) professor(a), inicialmente, pode pedir para que cada aluno(a) diga o dia e o mês em que nasceu e que cole no calendário a ficha-bolo em cima do dia e mês que nasceu. Observe que trata-se de um calendário qualquer, o objetivo é apenas que o(a) aluno(a) possa, visualmente, identificar o mês com o maior número de nascimentos, considerando somente a turma da sala de aula dele. Neste caso, será necessário destacar que há alunos que nasceram no mesmo dia, Antonio e Gabrielli, e Beatriz e Bianca, então haverá bolos sobrepostos no calendário. A partir das informações da Tabela 1, a representação obtida no calendário será similar à Figura 2.

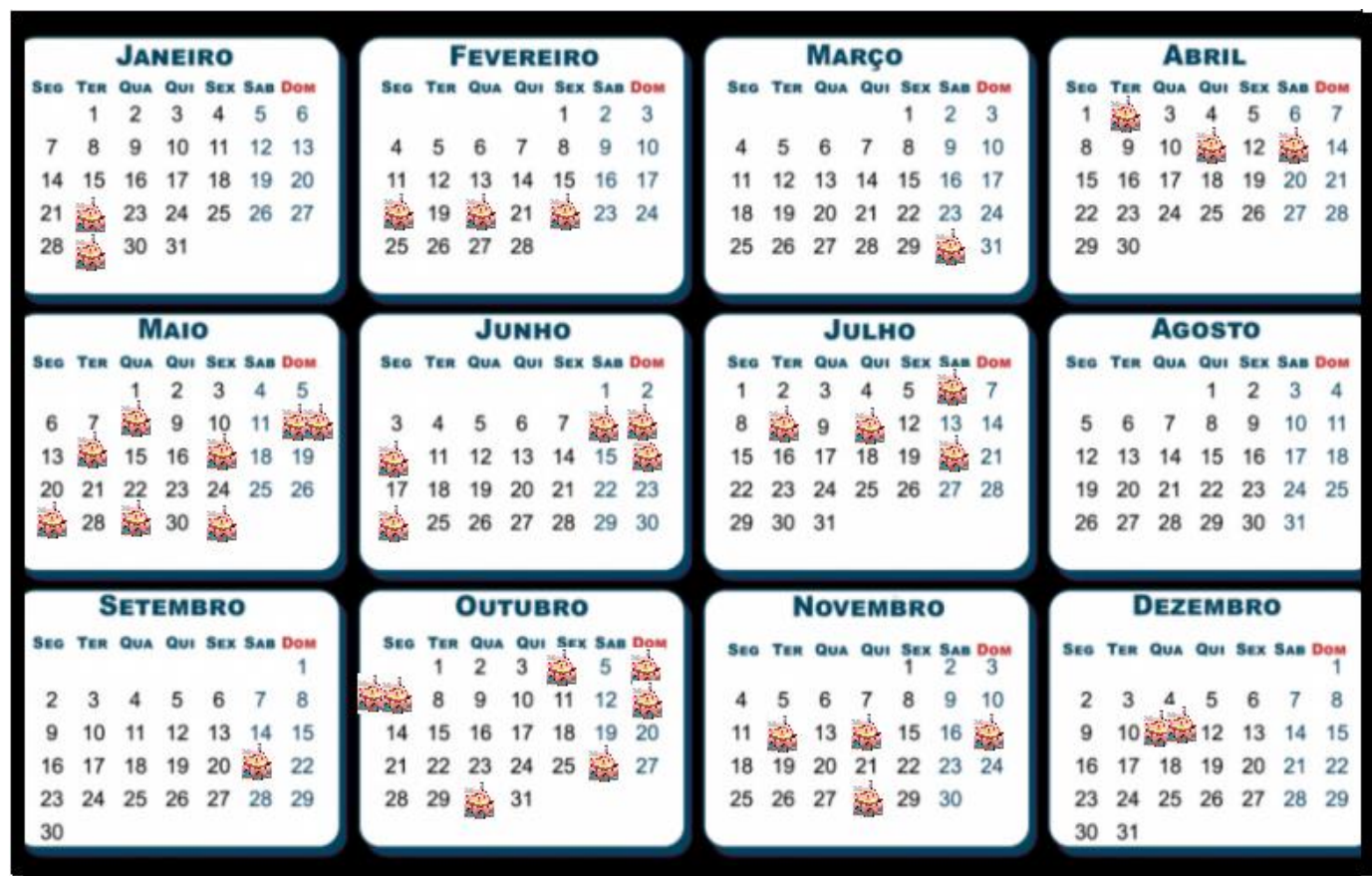

Figura 2: Calendário com dias e meses de aniversários marcados

Este é um estudo descritivo, pois todos alunos da turma estão sendo questionados em relação à sua data de nascimento, mas está se considerando apenas o mês de aniversário, assim, esta característica é a variável de interesse, que será chamada de variável estatística, e trata-se de uma variável de tipo qualitativo. Aqui pode ser interessante fazer questionamentos como: qual mês apresenta mais nascimentos para esta sala? Qual mês apresenta menos 
nascimentos? Qual é a desvantagem da representação apresentada com o calendário?

Note que o próprio calendário resulta numa representação informal e que contagem pode não ter sido tão simples, pois houve bolos sobrepostos. Na etapa a seguir, o(a) professor(a) pode propor que os alunos construam um gráfico de pontos bem grande, de modo que pudesse ser fixado na lousa. Os meses poderiam ser representados no eixo horizontal, como o apresentado na Figura 3, com as fichas que receberam posicionadas sobre os meses.

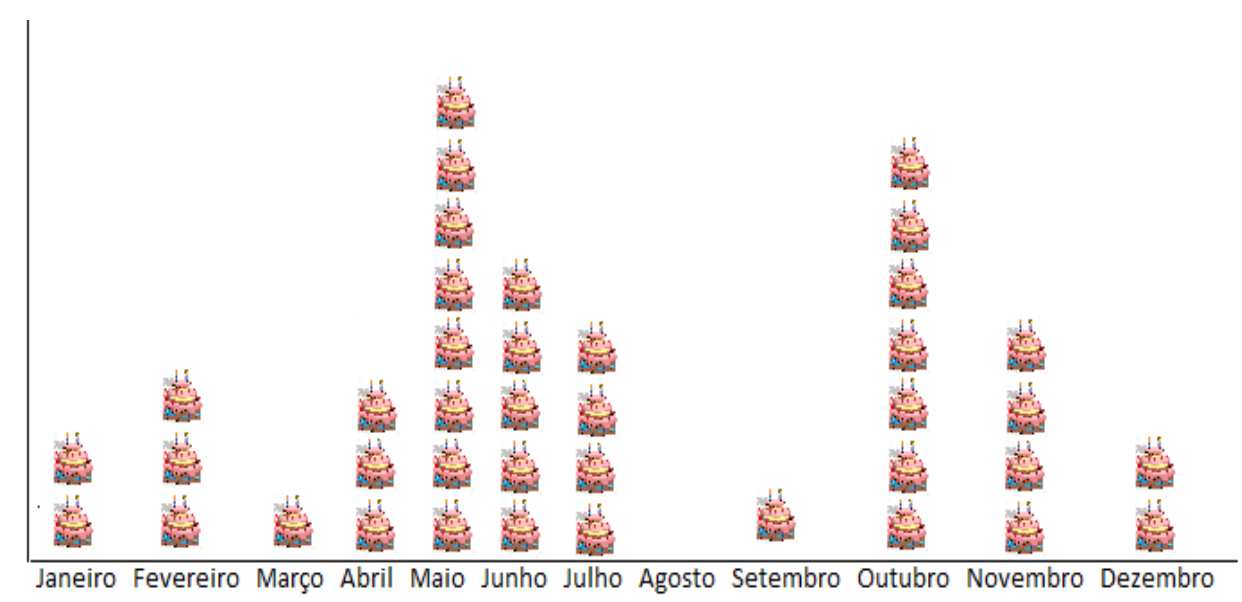

Figura 3: Gráfico dos meses em que os alunos da turma fictícia $S$ nasceram

Posteriormente, podem registrar as informações em uma tabela. Isto permitirá ao(à) aluno(a) a leitura do gráfico e construção da Tabela 2, que é chamada de tabela de frequência absoluta.

Tabela 2: Quantidade de alunos que nasceram em cada mês, na turma fictícia $S$

\begin{tabular}{l|l|l|l|l|l|l|l|l|l|l|l|l}
\hline Mês de nascimento & Jan & Fev & Mar & Abr & Mai & Jun & Jul & Ago & Set & Out & Nov & Dez \\
\hline Número de alunos & 2 & 3 & 1 & 3 & 8 & 5 & 4 & 0 & 1 & 7 & 4 & 2 \\
\hline
\end{tabular}

Consideremos o experimento simples de sortear apenas um aluno: quantos resultados possíveis têm este experimento? Espera-se que respondam 40 resultados.

A seguir o(a) professor(a) pode perguntar: se um aluno da turma é sorteado, em que mês acham que ele possa fazer aniversário? Este é um novo experimento, diferente do anterior, porque além de se sortear o aluno, observa-se seu mês de aniversário, neste caso, o número máximo de resultados possíveis será 12.

Sabemos que o conceito de variável aleatória está diretamente relacionado ao de probabilidade, o(a) professor(a) poderá fazer algumas perguntas, como por 
exemplo: quantos alunos estão presentes na sala? Desses alunos, quantos nasceram no mês de janeiro? E no mês de março?

$\mathrm{O}$ (a) professor(a) poderá perguntar: se se sorteia uma criança no Brasil, em que mês ela poderá fazer aniversário? É preciso realizar o sorteio para saber todas as possibilidades? Com este último questionamento trabalhará a noção de espaço amostral, sem chegar a formalizar o mesmo, nem se quer fazer um registro, apenas as respostas serão de maneira oral.

O próximo passo ou avanço será que o(a) aluno(a) possa quantificar a incerteza, a qual possa surgir diante de uma pergunta, tal como: um aluno sorteado desta sala tem mais probabilidade de nascer em junho ou novembro? Da simples observação da tabela de frequências ele, possivelmente, responderá junho. Nesse caso, a ideia de equiprobabilidade, isto é, a probabilidade de nascer num determinado mês é a mesma para qualquer mês, estará presente de maneira implícita.

Este pode ser o momento em que seja apresentada a noção de variabilidade, incerteza e amostra, com questionamentos tais como: será que os resultados serão os mesmos se considerarmos os alunos de outra escola? De outro período? Propor a seguinte questão: se sortearmos um aluno, ao acaso, da turma da série seguinte, em qual mês é mais provável que ele faça aniversário? Pedir que o(a) aluno(a) tente elaborar uma justificativa para a resposta que ele der.

Agora pode-se propor que se faça o seguinte experimento, que chamaremos de aleatório: sortear 5 alunos da turma e repetir o experimento 3 vezes. Os resultados obtidos em cada repetição do experimento aleatório foram os seguintes mostrados nas Tabelas $3-5$.

Tabela 3: Repetição 1

\begin{tabular}{ll}
\hline MICAEL & 28 de novembro \\
LUIZA & 31 de maio \\
ANTONIO & 14 de outubro \\
FRANCISCO & 26 de outubro \\
MIKAELLA & 14 de novembro \\
\hline
\end{tabular}

Tabela 4: Repetição 2

\begin{tabular}{ll}
\hline ALICE & 11 de dezembro \\
BEATRIZ & 20 de fevereiro \\
ISABELA & 9 de junho \\
IGOR & 11 de abril \\
LEONARDO & 16 de junho \\
\hline
\end{tabular}

Tabela 5: Repetição 3

\begin{tabular}{ll}
\hline SAMARA & 27 de maio \\
EDUARDO & 17 de novembro \\
RAISSA & 30 de março \\
NICOLAS & 17 de maio \\
TIAGO & 29 de maio \\
\hline
\end{tabular}

As frequências para a variável ou característica "mês de aniversário", para cada uma das repetições do experimento estão apresentadas na Tabela 6. 
Tabela 6: Quantidade de alunos que nasceram em cada mês, nas 3 repetições do experimento aleatório, na turma fictícia $S$

\begin{tabular}{l|l|l|l|l|l|l|l|l|l|l|l|l}
\hline Mês de nascimento & Jan & Fev & Mar & Abr & Mai & Jun & Jul & Ago & Set & Out & Nov & Dez \\
\hline Repetição 1 & 0 & 0 & 0 & 0 & 1 & 0 & 0 & 0 & 0 & 2 & 2 & 0 \\
Repetição 2 & 0 & 1 & 0 & 1 & 0 & 2 & 0 & 0 & 0 & 0 & 0 & 1 \\
Repetição 3 & 0 & 0 & 1 & 0 & 3 & 0 & 0 & 0 & 0 & 0 & 1 & 0 \\
\hline Total & 0 & 1 & 1 & 1 & 4 & 2 & 0 & 0 & 0 & 2 & 3 & 1 \\
\hline
\end{tabular}

O(a) professor(a) pode motivar a reflexão sobre a variação dos resultados segundo a repetição, perguntando: o mês com um número maior de aniversários é o mesmo em todas repetições? Na turma (Tabela 2), maio foi o mês com um maior número de aniversários (8), por que isto não ocorreu nas repetições 1 e 2 ?

Assim, o(a) professor(a) poderá, com esta atividade, apresentar a noção de censo, quando se considera todos os alunos da turma, e de amostra, ao realizar o experimento do sorteio que, realizado de maneira repetida, facilitará a ideia de variabilidade amostral, assim como, também, poder-se-á trabalhar a ideia de variabilidade ao associar as diferentes frequências com que uma variável de interesse, no caso mês de aniversário, apresenta-se quando considera-se um experimento aleatório.

De acordo com a BNCC, espera-se que os alunos de 6ำ ano já trabalhem com frações e consigam representar a fração em número decimal. Poderá, então, ser considerado como próximo passo, apresentar as noções iniciais de probabilidade frequentista e clássica.

Ainda no $6^{\circ}$ ano, a BNCC menciona de forma clara noções iniciais de probabilidade frequentista e clássica (Habilidade EF06MA30): "calcular a probabilidade de um evento aleatório, expressando-a por número racional (forma fracionária, decimal e percentual) e comparar esse número com a probabilidade obtida por meio de experimentos sucessivos."

No Ensino Fundamental - Anos Finais, o estudo deve ser ampliado e
aprofundado, por meio de atividades nas quais os alunos façam experimentos
aleatórios e simulações para confrontar os resultados obtidos com a
probabilidade teórica - probabilidade frequentista. (BRASIL, 2017)

Consideremos, primeiro, a definição clássica de probabilidade, em que se tem mesma probabilidade para cada resultado, equiprobabilidade, dada pelo número de casos favoráveis em relação ao número de casos possíveis. Suponhamos que se considera a turma $S$ como uma população de alunos, se um aluno é sorteado ao 
acaso dessa população, a probabilidade de que ele tenha nascido no mês de junho será 5/40=0,125; mas, se suspeitasse que a restrição de equiprobabilidade não é verdadeira, seria preciso repetir o sorteio várias vezes, isto é, repetir o experimento, e então deverá ser abordada a concepção frequentista de probabilidade. Assim, a partir da Tabela 6 , pode-se calcular que a frequência relativa observada para o mês de junho, considerando as três amostras selecionadas, foi $2 / 15=0,1333 \ldots$

Logo, sortear um aluno e observar seu mês de aniversário - experimento pode-se atribuir a cada mês - elemento do espaço amostral - uma probabilidade, ainda que não esteja definida de que maneira.

\subsubsection{Exemplo 2: Letras dos nomes}

Em uma primeira etapa da atividade, o(a) professor(a) poderá despertar a curiosidade dos alunos dizendo se o nome dele(a) (aluno(a)) é "mais extenso" ou "menos extenso" que qualquer outro nome dos alunos da sala. Começará ali a discussão do significado atribuído à palavra extenso, e a turma poderá chegar ao consenso que depende do número de letras. A seguir o(a) professor(a) começa pedindo que cada aluno(a) declare a quantidade de letras de seu primeiro nome, sem se importar qual este seja, ainda que existam nomes repetidos e, na lousa, o(a) professor(a) poderá ir marcando, isto é, registrando a resposta de cada aluno(a), informalmente, sem contagem, para que toda turma acompanhe, conforme apresentado no Quadro 1 para a turma fictícia $S$.

Quadro 1

\begin{tabular}{l|l}
\hline $\begin{array}{l}\text { Número de letras } \\
\text { do primeiro nome }\end{array}$ & $\begin{array}{l}\text { Quantidade de alunos(as) que possui esse } \\
\text { número de letras no primeiro nome }\end{array}$ \\
\hline 3 & || \\
\hline 4 & || $\mid$ \\
\hline 5 & |||||||| \\
\hline 6 & |||||||| $\mid$ \\
\hline 7 & |||||||||| \\
\hline 8 & |||||| $\mid$ \\
\hline 9 & || $\mid$ \\
\hline
\end{tabular}

Em seguida, procede-se a contagem que ocorreu em cada quantidade diferente de letras, para apresentar a Tabela 7. 
Tabela 7: Distribuição do número de letras do $1^{\circ}$ nome dos alunos na turma fictícia $S$

\begin{tabular}{l|llllllll|l}
\hline Número de letras do 1‥ Nome & 3 & 4 & 5 & 6 & 7 & 8 & 9 & 10 & Total \\
\hline $\begin{array}{l}\text { Quantidade de alunos que possui } \\
\text { esse } \mathrm{n}^{\circ} \text {. de letras no } 1^{\circ} \text {. nome }\end{array}$ & 2 & 3 & 7 & 8 & 10 & 6 & 3 & 1 & 40 \\
\hline
\end{tabular}

Notemos que ainda trata-se de um estudo descritivo, dado que, como no exemplo anterior, todos os alunos da turma estão sendo questionados, desta vez em relação ao número de letras de seu primeiro nome, porém, neste caso, a variável estatística é uma variável de tipo quantitativo.

Neste momento, o(a) professor(a) pode questionar ou chamar atenção dos(as) alunos(as) que a característica que está sendo analisada de cada aluno não é o nome e sim a quantidade de letras de seu nome. Se fosse o nome, seria uma variável qualitativa. Local de nascimento e mês de aniversário, por exemplo, são também ambas características qualitativas. Espera-se que os alunos, com alguma ajuda do(a) professor(a), percebam que o que cada aluno responde é um número, que é a quantidade de letras do seu primeiro nome, que nessa turma fictícia $S$ variou de $3,4,5,6,7,8,9$ e 10.

Identificada a variável quantitativa, o(a) professor(a) pode realizar algumas das indagações: qual tamanho do primeiro nome é o mais frequente; e qual é o menos frequente; quantas letras têm o maior nome (que corresponde ao máximo valor da variável); qual é o número de letras do nome mais curto (que corresponde ao mínimo da variável). Desta maneira podem ser apresentadas as noções de variabilidade e de amplitude.

Neste exemplo de variável quantitativa, algumas outras quantidades podem ainda ser de interesse; poderia perguntar: quantos alunos têm 7 letras ou mais no seu primeiro nome; quantos(as) alunos(as) têm até 5 letras (ou de forma diferente, quantos alunos têm 5 letras ou menos)?

Os resultados da Tabela 7 poderão ser representados por um gráfico, como o apresentado na Figura 4.

Este exemplo poderá ser também trabalhado com alunos do $7^{\circ}$. ano do ensino fundamental.

As noções de incerteza e probabilidade podem ser abordadas, questionando se sorteamos uma pessoa do Brasil podemos saber quantas letras terá seu primeiro nome? Por exemplo, Juvenaldina, tem 11 e Eraldonclóbes tem 12 letras. 
Suponhamos que ela nasceu em 2002, ano em que o Brasil foi campeão da Copa, o número 7 tem uma maior probabilidade pelo nome Ronaldo?

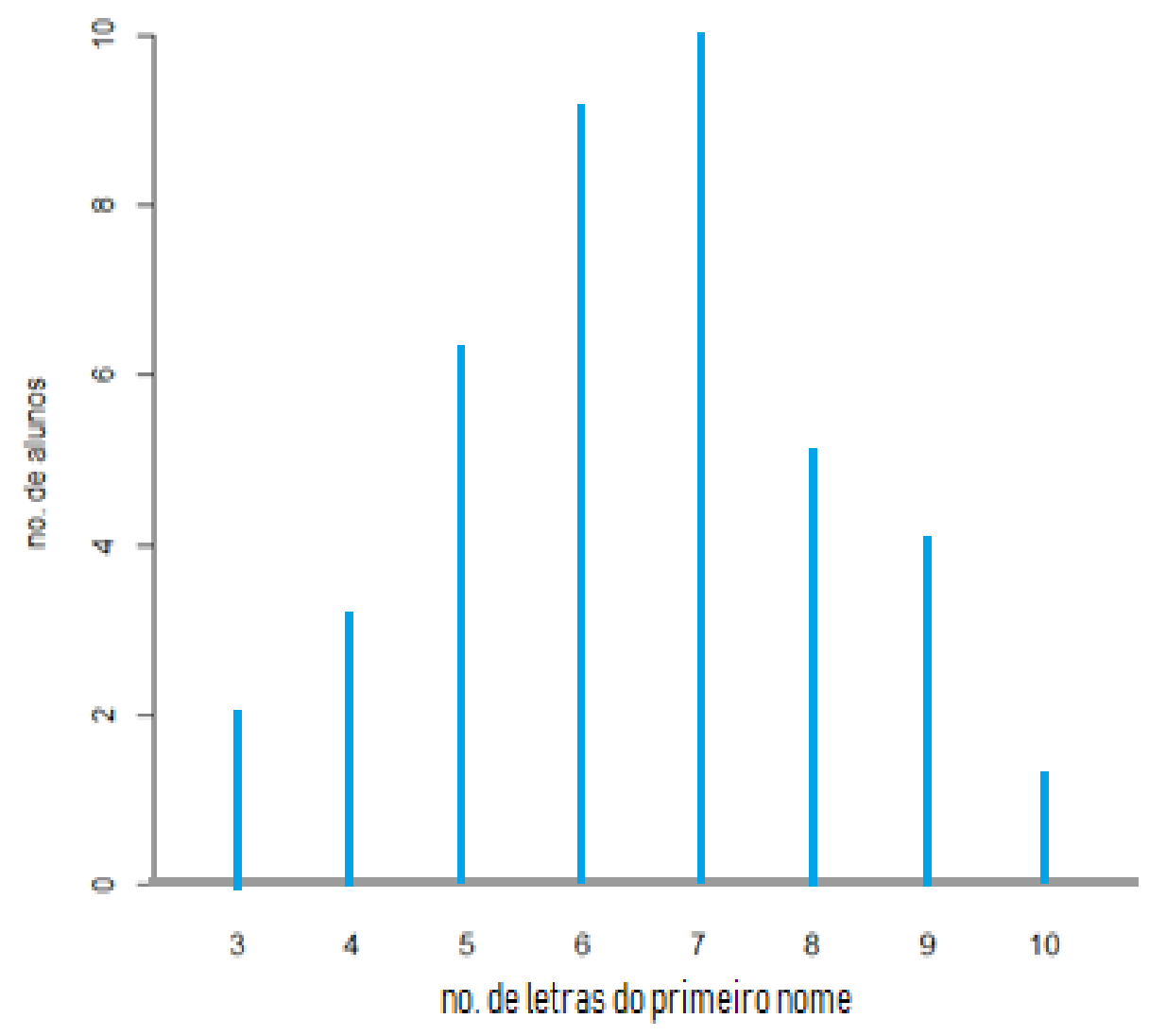

Figura 4: Gráfico do número de letras do 1ํnome

A seguir, pode-se formular a experiência ou ação de sortear uma pessoa no Brasil, decidir que será um "evento pouco provável" que o nome tenha mais de 15 letras, e é impossível nome com uma letra.

Apenas posteriormente, pode-se definir uma nova experiência de sortear um(a) aluno(a) da turma $S$, e decidir o que é mais provável, o(a) aluno(a) ter 7 letras ou 8 letras no primeiro nome? Espera-se que o(a) aluno(a) responda a partir da observação da tabela de frequências (Tabela 7).

Nesta outra etapa, o(a) professor(a) poderá motivar os alunos a escrever todos os resultados possíveis do experimento: sortear um(a) aluno(a) da turma $S$ e verificar o número de letras. O resultado será o conjunto formado pelos números 3 , $4,5,6,7,8,9$ e 10, o qual é denominado, espaço amostral $\Omega=\{3,4,5,6,7,8,9$, $10\}$. 
A seguir o(a) professor(a) pode formular a seguinte questão: podemos definir o espaço amostral do experimento que consiste em sortear uma pessoa no Brasil e registrar o número de letras do primeiro nome? Se a resposta for afirmativa, quantos elementos este teria? Todos os elementos são igualmente prováveis?

$\mathrm{O}$ (A) professor(a) pode propor uma atividade a partir das informações coletadas no Censo pelo IBGE, em relação aos nomes, em https://censo2010.ibge.gov.br/nomes/\#/search (acesso em 09 de agosto de 2019).

Agora pode-se propor que se faça o seguinte experimento, que chamaremos de experimento aleatório: sortear 5 alunos da turma e repetir o experimento 3 vezes, registrando o número de letras de seu primeiro nome obtido em cada caso. Os resultados em cada repetição do experimento aleatório foram os seguintes mostrados nas Tabelas $8-10$.

Tabela 8: Repetição 1

\begin{tabular}{ll}
\hline MICAEL & 6 \\
LUIZA & 5 \\
ANTONIO & 7 \\
FRANCISCO & 9 \\
MIKAELLA & 8 \\
\hline
\end{tabular}

Tabela 9: Repetição 2

ALICE 5

EDUARDO 7

ISABELA 7

IGOR 4

LEONARDO 8
Tabela 10: Repetição 3

\begin{tabular}{ll}
\hline SAMARA & 6 \\
EDUARDO & 7 \\
RAISSA & 6 \\
NICOLAS & 6 \\
TIAGO & 5
\end{tabular}

As frequências para a variável número de letras do primeiro nome, de cada uma das repetições do experimento, estão apresentadas na Tabela 11.

$\mathrm{O}$ (A) professor(a) pode motivar a reflexão sobre a variação dos resultados segundo a repetição, perguntando o número de letras mais frequente é o mesmo em todas repetições? Na turma $S$, o número 7 foi o que teve uma frequência maior, por que isto não ocorreu nas repetições?

A seguir o(a) professor(a) pode formular a seguinte situação-problema: o que aconteceria caso se realizassem 10 repetições e o nome Francisco aparecesse em todas elas? Isto motivará a reflexão de como trabalhar com frequências pode não ser suficiente para a atribuição de probabilidades. Assim, o(a) professor(a) poderá retomar o conceito de equiprobalidade, e as definições de probabilidade clássica e frequentista, pois existem situações dentro desta atividade que permitem abordar estes temas. 
Tabela 11: Frequências do número de letras do nome dos alunos sorteados da turma $S$, nas 3 repetições do experimento aleatório

\begin{tabular}{l|l|l|l|l|l|l}
\hline Número de letras do 1ํำ nome & 4 & 5 & 6 & 7 & 8 & 9 \\
\hline Repetição 1 & 0 & 1 & 1 & 1 & 1 & 1 \\
Repetição 2 & 1 & 1 & 0 & 2 & 1 & 0 \\
Repetição 3 & 0 & 1 & 3 & 1 & 0 & 0 \\
\hline Total & 1 & 3 & 4 & 4 & 2 & 1 \\
\hline
\end{tabular}

Logo, o próximo passo será a apresentação da definição de variável aleatória, uma vez que já foram abordados os conceitos de experimento, espaço amostral e de probabilidade, que irá, assim, transformar a variável característica em variável aleatória.

Para finalizar, notemos que o(a) professor(a) poderá, com esta atividade, novamente reforçar a noção de censo, quando se considera todos os(as) alunos(as) da turma $S$, e de amostra, ao realizar o experimento de maneira repetida, ou ao sortear uma pessoa do Brasil. Também, de maneira organizada e estabelecendo relações, poderá abordar os conceitos de variável estatística e variável aleatória.

As diferentes etapas desta atividade poderão ser desenvolvidas numa única série (ano) ou em várias, ao longo do tempo, segundo seja o currículo escolar adotado.

Ainda neste exemplo, para finalizar, o(a) professor(a) poderá pedir para que o(a) aluno(a) contabilize as palavras diferentes de uma charge, ou um texto curto, como um conto ou poema. Na Figura 5, colocamos o exemplo de uma charge do cartunista e professor Dorinho ${ }^{1}$, e o(a) professor(a) pode pedir que os alunos calculem a frequência de vogais no texto. Isto seria uma aproximação da probabilidade que uma vogal apareça num texto em português? Note que por conter palavras pertencentes a outro idioma, o(a) professor(a) pode perguntar: será que

1 Heliodoro Teixeira Bastos Filho, possui graduação em Arquitetura pela Universidade Braz Cubas (1974). Mestrado (1984) e doutorado (1992), ambos em Ciências da Comunicação pela Escola de Comunicações e Artes da Universidade de São Paulo. Desde 1976 é professor do Curso de Publicidade da Escola de Comunicações e Artes/ECA-USP. É professor nos cursos de pósgraduação GESTCORP/ECA-USP, Gestão de Comunicação e Marketing/ECA-USP, da FIA/Fundação Instituto de Administração, do INPG/Instituto Nacional de Pós Graduação e da SUSTENTARE/Escola de Negócios. Além da área acadêmica é sócio diretor do estúdio Dorinho Bastos Comunicação \& Design e cartunista, com trabalhos publicados em vários veículos de comunicação, principalmente aos ligados ao mercado de Propaganda e Marketing. http://www2.eca.usp.br/crp/docentes/dorinho$\underline{\text { bastos/ }}$ 
haveria diferença com a probabilidade das mesmas letras em português? Note que por conter palavras pertencentes a outro idioma, o(a) professor(a) pode perguntar: será que haveria diferença com a probabilidade das mesmas letras em português? Também poderá colocar questões, tais como: qual é probabilidade de que alguém da sala de aula tenha um perfil no Facebook? E que tenha um blog? E no Instagram?

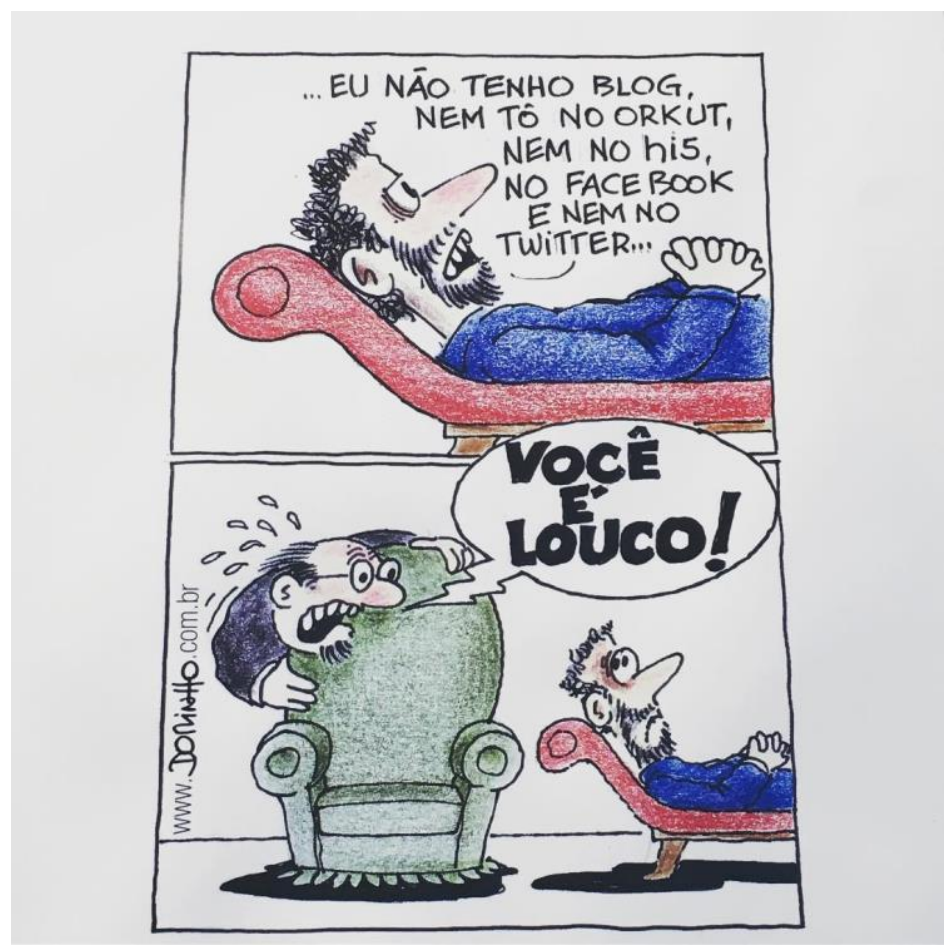

Figura 5

Poderá motivar os(as) alunos(as) a pesquisar dois autores, um deles que use muitas palavras e outro que use menos palavras diferentes em poemas, relacionados com um mesmo tema, por exemplo, a amizade ou o amor. Com esta atividade o(a) professor(a) poderá analisar as diferenças entre as características de autores, gêneros ou de movimentos literários diversos.

Para descontrair, se o(a) professor(a) achar pertinente, pode comentar que algumas pessoas atribuem um significado oculto aos nomes e que este pode ter influência na vida destas, isto chama-se numerologia e esta analisa as letras contidas no nome de nascimento. De acordo com o jornalista e numerólogo Felipe Porto, no Brasil, é marcante a falta das letras $H, Q$ e $Z$ no nome das pessoas. Conforme a numerologia Pitagórica (além de físico, matemático, astrônomo, etc., Pitágoras era um místico, astrólogo e numerólogo), todas essas três letras valem 8 e esse número está associado ao poder e riqueza. 
Pitágoras tornou-se uma figura legendária: filósofo, profeta, sábio, místico e político. Há controvérsias sobre seus feitos, pois não há registros desta época, apenas informações obtidas muito tempo depois, às vezes séculos depois (BARON, 1985).

De acordo com Silva (2004), a Numerologia é um campo de conhecimento cujo estatuto científico é bastante controvertido, no entanto, para ilustrar e descontrair a aula, o professor(a) pode comentar que em busca de boas vibrações, por exemplo, a atriz Sheron Menezes aderiu ao estudo dos números e alterou a grafia do sobrenome para Menezzes, com dois z buscando fama, evidencia e sucesso. $\quad<$ http://www.portaldf.com.br/jornal/materias/numerologo-diz-que-mudabrasil/> (acesso em 27 de setembro de 2019).

\subsubsection{Exemplo 3: Máquina Caseira de Galton}

Essa atividade foi desenvolvida com o objetivo de ser aplicada para alunos(as) de $9^{\circ}$ ano, sempre com uma perspectiva de currículo em espiral.

A máquina de Galton é basicamente uma placa de madeira com um arranjo de pregos, dispostos em intervalos iguais, atuando como obstáculos à passagem de bolinhas. Na parte superior da placa, há um "funil" para o armazenamento de esferas e na parte inferior várias canaletas onde as bolinhas são armazenadas. Quando essas bolinhas são liberadas, elas se chocam com os pregos e se acumulam em uma série de canaletas cuja distribuição resultante é semelhante a uma curva normal.

Para iniciar a atividade, iremos apresentar a máquina de Galton (preferencialmente em material manipulável) e propor que os alunos construam uma versão bem simples com apenas dois compartimentos e um pino. Por se tratar de uma abordagem para alunos(as) de 9o ano, iremos, sempre que possível, retomarmos conteúdo dos anos anteriores, porém com um refinamento maior.

O primeiro passo é a construção do material, que o professor pode fazer ou orientar os alunos para que façam em grupos, para que cada grupo tenha sua máquina. O material é bem simples: bolinhas, um alfinete com cabeça grande, isopor, papel de transparência (ou um plástico duro transparente ou translúcido), papel quadriculado, canudos e cola. A ideia é que fique parecido com o modelo da Figura 6, no qual em vermelho estão representados os canudinhos e em verde o 
alfinete. A transparência é utilizada para cobrir a máquina e evitar que as bolinhas saiam da máquina, o isopor serve de base, nele serão grudados os canudos, espetado o alfinete, colocado o papel quadriculado e por fim coberto com o material transparente.

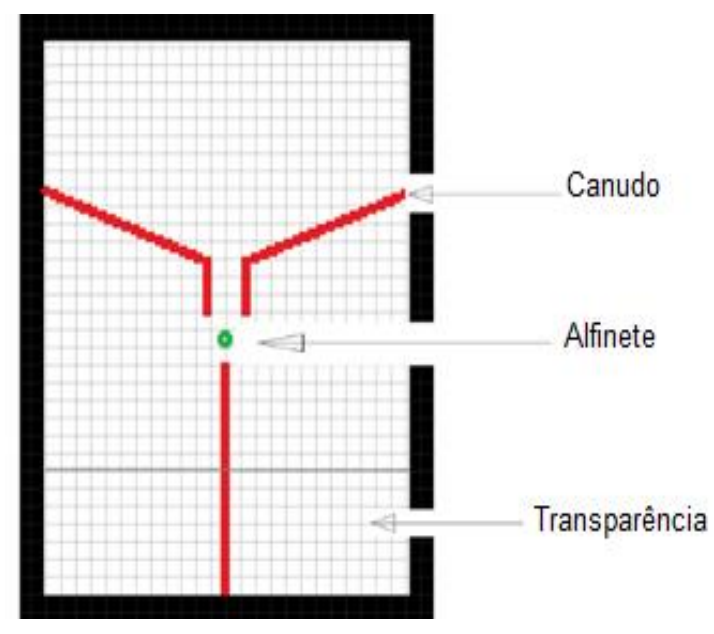

Figura 6

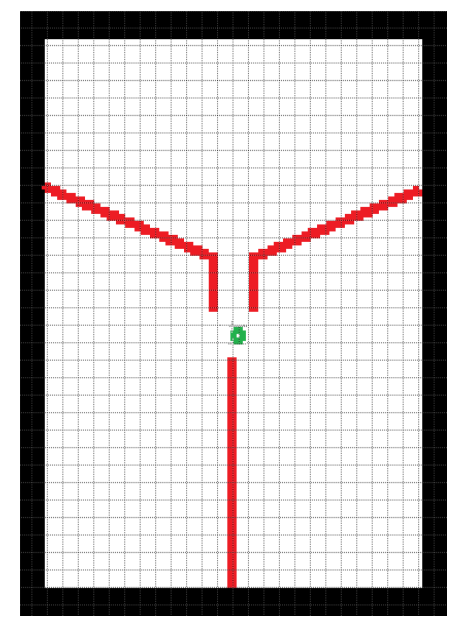

Figura 7

Com o alfinete centralizado, como mostrado na Figura 6, a atividade inicial será: soltarmos várias bolinhas e observarmos qual é o comportamento dessas bolinhas, em termos do lado que irão se deslocar. $O(A)$ professor(a) poderá questionar qual dos lados tem maior probabilidade de cair mais bolinhas e o aluno irá responder, por hora, mediante a observação. Em uma segunda etapa, o professor deve deslocar o alfinete (mais para direita ou para esquerda) como apresentado na Figura 7. É possível observar na Figura 8 como fica a máquina após sua construção.

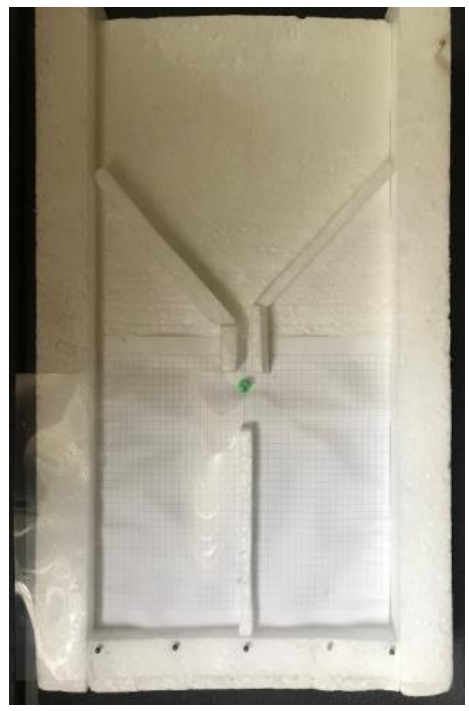

Figura 8 
Observe que deslocamos o alfinete mais para direita na Figura 7, então outro questionamento que pode ser feito é: qual dos lados terá mais bolinhas? Apesar de ser uma atividade de expressão oral, deseja-se que o aluno sempre se justifique de maneira adequada.

Em conjunto com os alunos, espera-se que a classe diga que na primeira etapa as possibilidades de as bolinhas irem para esquerda ou para direita sejam iguais; já na segunda, é mais provável que as bolinhas caiam para esquerda, pois o alfinete foi deslocado para direita. No primeiro caso as probabilidades são iguais, portanto, denominamos evento equiprovável.

Uma proposta bastante interessante é propor aos alunos que estimem quantas bolinhas tem em cada lado, sem contar. Podem surgir várias propostas para realizar isto; como o papel estará quadriculado, pode-se sugerir que contem quantas bolinhas há em determinada área e assim, por meio desta, estimar as demais. $O$ professor pode comentar que um método parecido com este, porém setorizado, é utilizado para fazer a contagem de pessoas em eventos. Este método é conhecido como método de Jacobs.

O método de Jacobs, baseado no conceito de densidade de pessoas, é utilizado até os dias de hoje para a contagem de multidões estáticas. Este método ficou conhecido quando em 1967 o professor da Universidade da Califórnia Herbert Jacobs observava os alunos protestando contra a guerra do Vietnã. Basicamente ele contabilizou os alunos que ocupavam uma área conhecida, extrapolando a contagem para toda região do protesto. (BARROS, 2014).

Será que este método sempre dará certo? Existe alguma situação que ele pode falhar, como por exemplo, em um trio elétrico em Salvador, as pessoas estão distribuídas igualmente ou existe maior concentração de pessoas mais próximo do trio?

$\mathrm{O}$ (a) professor(a) poderá, com a ajuda de uma colher, ir colocando em um copo de café pequeno as bolinhas de 10 em 10 até atingir 100 bolinhas, ali se fará uma marca limite no copo como no esquema a seguir, tomando cuidado de não deixar espaços vazios. Assim este copinho com a marca será utilizado como instrumento de medida.

No entanto, no segundo caso, suponhamos que das 1000 bolinhas que foram lançadas, temos em um quadradinho de $1 \mathrm{~cm}^{2}$ de área, 10 bolinhas, e foi ocupado do 
lado direito $30 \mathrm{~cm}^{2}$. Assim, sabemos que do lado direito teremos 300 bolinhas, já do lado esquerdo, as bolinhas ocuparam $70 \mathrm{~cm}^{2}$, logo teremos, aproximadamente, 700 bolinhas. A probabilidade de as bolinhas irem para o lado direito será estimado por $300 / 1000=0,3$ e de irem para o lado esquerdo será de 700/1000 $=0,7$. Na BNCC, sugere-se que 0 aluno do $7^{\circ}$ ano seja capaz de fazer uma estimativa de probabilidade por meio de frequência de ocorrências (EF07MA34).

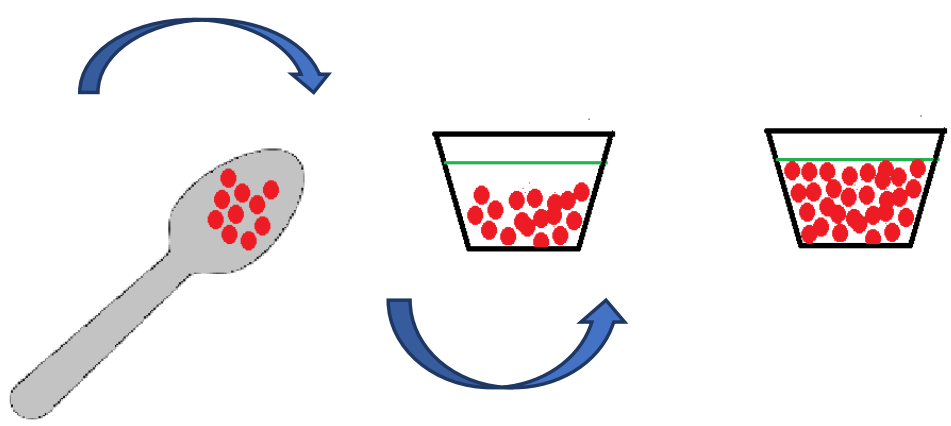

Figura 8

Em um próximo passo, poderiam ser colocadas bolinhas coloridas e poderia ser solicitado aos alunos organizassem uma tabela, inicialmente, para o caso em que o alfinete estivesse no meio e, depois, para o alfinete deslocado, contendo as cores e as quantidades de bolinhas de cada cor. Posteriormente, o(a) professor(a) poderá pedir para que o aluno mova ainda mais o alfinete e repita a experiência, assim poderá concluir efetivamente que não são mais eventos equiprováveis. 


\section{Formalizando o Conceito com aplicações}

No Capítulo 3 apresentamos exemplos que, fazendo uso de uma abordagem em espiral, proporciona ao aluno condições de se apropriar, de maneira intuitiva, de conceitos como espaço amostral, variável estatística do tipo quantitativo e qualitativo, censo, amostra, probabilidade e variável aleatória. Neste capítulo, como um passo à frente, formalizamos esses conceitos e nos aprofundamos nos demais. Por fim faremos uma breve apresentação de como variáveis aleatórias são abordadas no ensino superior.

A primeira definição a ser apresentada é a de espaço amostral, sempre utilizando os exemplos apresentados anteriormente.

\subsection{Sistematizando}

O espaço amostral representa nada mais do que o conjunto dos resultados possíveis quando um experimento aleatório é realizado.

No Exemplo 3.1.1, o experimento aleatório foi sortear um(a) aluno(a) dessa turma particular $S$ e verificar em qual mês ele(a) tinha nascido. $O$ (a) aluno(a) poderia ter nascido em qualquer mês do ano, com exceção do mês de agosto. Indicando por $\Omega$ o espaço amostral, temos:

$\Omega_{1}=$ \{janeiro, fevereiro, março, abril, maio, junho, julho, setembro, outubro, novembro, dezembro\}.

Todo subconjunto do espaço amostral é chamado de evento, por exemplo:

$A$ : mês de aniversário nas férias de inverno, no hemisfério sul;

$B$ : meses que começam com a letra $J$.

Podemos representar $A=\{$ julho $\}$ e $B=\{$ junho, julho $\}$, note que $A$ e $B$ estão contidos em $\Omega$, portanto são subconjuntos de $\Omega$, logo são eventos. $O$ (a) professor(a) poderá perguntar: existem meses que se repetem nestes conjuntos? Que conjunto seria este? É também um evento?

Seja o evento $C$ : mês que acontece o Natal. Há meses em comum entre $B$ e $C$ ? O evento resultante será o conjunto vazio.

$O$ conjunto representando o evento $A$ é um conjunto unitário, contém um único mês, por isso é dito evento elementar ou simples. Quantos conjuntos unitários ou eventos elementares há no espaço amostral deste exemplo? 
Se pensarmos no experimento mais simples de sortear um aluno, o espaço amostral será o conjunto formado por todos os alunos da sala e cada aluno poderá ser considerado um evento elementar.

Para o Exemplo 3.1.2, conforme dito anteriormente, considerando o experimento sortear um(a) aluno(a) dessa turma específica e verificar o número de letras de seu $1^{\circ}$. nome, o espaço amostral é $\Omega_{2}=\{3,4,5,6,7,8,9,10\}$. Alguns eventos associados a este espaço amostral são:

$A$ : ter 7 letras no $1^{\circ}$. nome $=\{7\}$

$B$ : ter 8 letras ou mais no $1^{\circ}$. nome $=\{8,9,10\}$

Já no Exemplo 3.1.3, pode-se definir, por exemplo, o experimento liberar as bolinhas na máquina de Galton e verificar em qual lado elas caem, o espaço amostral, neste caso, é $\Omega_{3}=$ \{direito, esquerdo\}; no entanto, se o experimento consiste em liberar as bolinhas de cor azul, branca e vermelha e também observar as cores, então teríamos: $\Omega_{4}=\{A D, A E, B D, B E, V D, V E\}$, sendo que

$A D=$ ocorrência de bolinha azul do lado direito;

$A E=$ ocorrência de bolinha azul do lado esquerdo;

$B D=$ ocorrência de bolinha branca do lado direito;

$B E=$ ocorrência de bolinha branca do lado esquerdo;

$V D=$ ocorrência de bolinha vermelha do lado direito;

$V E=$ ocorrência de bolinha vermelha do lado esquerdo.

Para definir este espaço amostral é necessário executar o experimento? Em algum dos exemplos citados, faz-se necessário a realização do experimento de maneira concreta para definir o espaço amostral? No caso do sorteio de uma pessoa no Brasil nos dias de hoje e registrar o número de letras de seu primeiro nome, não é possível definir de maneira precisa o espaço amostral. Um exemplo simples, em que é necessário realizar o experimento para determinar o espaço amostral, pode ser colocar uma caixa fechada com objetos de várias cores diferentes, por exemplo, bolinhas. Os alunos desconhecem as cores existentes, assim, para determinar o espaço amostral, será necessário o sorteio sem reposição de todas as bolinhas.

Diversos problemas estão relacionados com variáveis aleatórias, desde elaborar hipóteses, determinar fatores que influenciam certa situação e, até mesmo, identificar certa característica de uma determinada população e a posterior tomada de decisões, com base a esta, se for o caso. A partir de uma ou mais variáveis aleatórias, por meio de funções, é possível definir nova variável aleatória (como 
soma, máximos, mínimos, entre muitas outras), bastando definirmos, claramente, qual é a variável aleatória que está sendo vinculada a um determinado experimento aleatório. Conforme mencionado, a noção de variável aleatória está ligada com outros conceitos, como função, espaço amostral, probabilidade, parâmetros, por isso não devemos considerar variável aleatória apenas como um conceito matemático e sim como a configuração de objetos matemáticos. Mais ainda, precisamos considerar este conceito também como uma poderosa ferramenta de resolução de problemas, quando se quer encontrar uma regra de formação, que atribua valores numéricos a um resultado de um experimento aleatório e que esteja de acordo com alguns critérios matemáticos - função - e vinculada a um contexto real.

Podemos fazer uma releitura do parágrafo anterior, enunciando uma definição formal: uma variável aleatória é uma função que associa um valor numérico a cada evento elementar do espaço amostral associado a certo experimento aleatório.

Retomando o experimento simples do Exemplo 3.1.1, que era sortear um aluno da sala $S$, como já foi dito, cada evento elementar será o próprio aluno e o espaço amostral, o conjunto de todos os alunos da sala, note que este espaço amostral é diferente de $\Omega_{2}=\{3,4,5,6,7,8,9,10\}$. Entretanto, pode-se pensar, também, que o número de letras do primeiro nome é uma variável aleatória associada ao experimento sortear um aluno da sala $S$, por exemplo, se a aluna sorteada for Raissa a ela se atribuirá o número 6, se o aluno sorteado for Leonardo, o número atribuído a ele será o 8 , e assim, o conjunto de valores assumidos pela variável aleatória número de letras do primeiro nome é $L=\{3,4,5,6,7,8,9,10\}$. Resulta interessante pensar na diferença na construção e interpretação dos conjuntos $\Omega_{2}$ e L.

Apesar das definições formais, que serão apresentadas a seguir, não se enquadrarem dentro do currículo do ensino fundamental e tratar-se de um conteúdo do ensino superior, nossa proposta é que este trabalho possa auxiliar o professor a ter uma visão mais aprofundada do assunto e a melhorar suas práticas docentes, além de apresentar os conceitos relacionados de maneira organizada, ainda que sucinta, de tal forma que as relações entre estes sejam visualizadas e apropriadas mais facilmente. Além disso, espera-se que este material possa contribuir na formação contínua do professor, pois esta abordagem é dificilmente apresentada, em geral, nas licenciaturas. 
As definições formais a seguir foram extraídas de James (1996) e relações com os conceitos básicos são apresentadas.

Definição 1. Seja $\Omega$ um espaço amostral associado a certo experimento aleatório. Todo subconjunto $A \subset \Omega$ será chamado de evento, $\Omega$ é o evento certo, $Q$ é o evento impossível, e se $w \in \Omega$, o conjunto unitário $\{w\}$ é dito evento elementar ou simples.

Se o experimento aleatório foi sortear um(a) aluno(a) de uma turma qualquer e verificar em qual mês ele(a) nasceu, o(a) aluno(a) poderia ter nascido em qualquer mês do ano, portanto, o conjunto todos os meses do ano seria o espaço amostral. Indicando por $\Omega$ o espaço amostral, o evento certo é dado por:

$\Omega=$ janeiro, fevereiro, março, abril, maio, junho, julho, agosto, setembro, outubro, novembro, dezembro\}.

Note que este espaço amostral é diferente daquele do Exemplo 3.1.1, pois foram determinados por experimentos diferentes, e teve, por exemplo, como consequência, que o evento elementar ou subconjunto unitário $A=\{$ agosto $\}$ pertence a $\Omega$ e não a $\Omega_{1}$.

Nossa próxima definição formal será de evento aleatório: todo evento que podemos atribuir uma probabilidade será chamado de evento aleatório. Um evento aleatório tem algumas propriedades e antes de formalizarmos, como para definição anterior, retomaremos os exemplos.

No exemplo anterior, $A=$ \{agosto $\}$ é um evento aleatório, pois se supomos que a probabilidade que uma criança nasça é a mesma para todos os meses, a probabilidade atribuída a $A$ será 1/12.

Analisando o Exemplo 3.1.2, o espaço amostral, como definido anteriormente, é $\Omega_{2}=\{3,4,5,6,7,8,9,10\}$. Considerando o evento sortear um aluno da sala $S$ e seu primeiro nome conter exatamente 6 letras, isto é, $M=\{6\}$, é um evento aleatório, pois pode-se atribuir a probabilidade $8 / 40=0,2$. Já a probabilidade de ocorrer um número diferente de 6 letras, ou seja, ocorrer o evento $M^{c}=\{3,4,5,7,8,9,10\}$, a ele atribui-se a probabilidade de ocorrência $2 / 40+3 / 40+7 / 40+10 / 40+6 / 40+3 / 40+1 / 40=$ $32 / 40=0,8$. Observe que $0,2+0,8=1$, ou de forma análoga, $1-0,2=1-P(M)=$ $P\left(M^{c}\right)=0,8$.

Num caso geral, dois eventos aleatórios, $A$ e $B$ são eventos complementares se a união deles é o próprio espaço amostral (evento certo) e a soma de suas 
probabilidades é 1. Sendo $M$ e $M^{c}$ como os definidos no parágrafo anterior, os eventos $M$ e $M^{C}$ são eventos complementares, pois sua união é o próprio espaço amostral e a soma de suas probabilidades é $1, P(M)+P\left(M^{c}\right)=1$

Antes de apresentarmos a próxima definição, retomemos o Exemplo 3.1.3, da máquina caseira de Galton. Considere uma máquina caseira de Galton com 1000 bolinhas, a probabilidade de essas bolinhas caírem do lado esquerdo, estando o alfinete posicionado no meio, é $1 / 2$, e de cair do lado direito, nas mesmas condições, é $1 / 2$. Agora, a probabilidade de as bolinhas caírem do lado direito ou esquerdo é dada por $1 / 2+1 / 2=1$, já que cair do lado direito ou cair do lado esquerdo são eventos complementares.

Definição 2. Seja $\mathscr{A}$ uma classe dos eventos aleatórios. Um evento $A$ da classe $\mathcal{A}$, o qual atribuímos uma probabilidade, será chamado de evento aleatório e estipulam-se as seguintes propriedades para a classe $\mathcal{A}$ :

A.1. $\Omega \in \mathcal{A}$, evidentemente temos que $P(\Omega)=1$.

A.2. Se $A \in \mathscr{A}$ então $A^{C} \in \mathcal{A}$, e portanto, $P\left(A^{c}\right)=1-P(A)$

A.3. Se $A \in \mathscr{A}$ e $B \in \mathscr{A}$, então $A \cup B \in \mathscr{A}$, isto é, atribuída uma probabilidade a $A$ e uma probabilidade a $B$ será atribuída uma probabilidade a " $A$ ou $B$ ".

Para o leitor se inteirar melhor, seguem algumas definições, que permitirão aprofundar no conceito de variável aleatória. Suponha que \& seja uma álgebra de eventos.

Definição 3. Seja $\Omega$ um conjunto não vazio. Uma classe $\mathcal{A}$ de subconjuntos de $\Omega$ satisfazendo A.1, A.2 e A.3 é chamada de álgebra de subconjuntos de $\Omega$.

Assim, dado um experimento e determinada a forma de atribuir probabilidades, é possível definir uma classe de conjuntos, tal que seja uma álgebra de conjuntos, é suficiente que satisfaça as propriedades anteriores, A.1, A.2, A.3.

No Exemplo 3.1.1, do mês do aniversário, determinados os subconjuntos elementares $\Omega_{1}$ (meses do ano) para poder ter definida a álgebra, basta considerar todos os conjuntos que resultam da união destes. Por exemplo, sejam os conjuntos $C=\{$ janeiro, fevereiro $\}$ resultou a união dos subconjuntos elementares $J=$ janeiro $\}$, e $F=\{$ fevereiro $\}$. Considerando agora $D=\{$ março, abril, maio $\}$, a álgebra também 
deverá conter o conjunto união de $C$ e $D$, isto é, $E=$ \{janeiro, fevereiro, março, abril, maio\}, e assim por diante.

Podemos pensar no Exemplo 3.1.2 apresentado anteriormente, que estuda a quantidade de letras do nome, a probabilidade de se sortear um aluno, ao acaso, e o mesmo ter 4 letras em seu nome é $3 / 40$, enquanto que, a probabilidade de se sortear outro aluno, ao acaso, e este ter 5 letras em seu nome é $7 / 40$. Note que um aluno poderá ter ou 4 ou 5 letras, mas não os dois números de letras ao mesmo tempo, então os eventos $D=\{4\}$ e $C=\{5\}$ são disjuntos, e se quisermos a probabilidade de ao sortear, ao acaso, um aluno desta mesma turma ele ter 4 ou 5 letras em seu nome, ou seja, $C \cup D=\{4,5\}$, será $10 / 40=1 / 4$. Esse exemplo ilustra o Axioma 3 da Definição 3.

Considere, agora, a seguinte propriedade para a classe $\mathcal{A}$ de subconjuntos:

A.3'. Se $A_{n} \in \mathcal{A}$, para $n=1,2,3, \ldots$, então $\bigcup^{\infty}{ }_{n=1} A_{n} \in \mathcal{A}$.

Definição 4. Seja $\Omega$ um conjunto não-vazio. Uma classe $\mathcal{A}$ de subconjuntos de $\Omega$ satisfazendo A.1, A.2 e A.3' é chamada de $\sigma$-álgebra de subconjuntos de $\Omega$.

Convém mencionar que uma $\sigma$-álgebra é uma álgebra, pois a propriedade $\mathrm{A} 3$ é consequência de $A 3^{\prime}$, porque podemos considerar $A \cup B=A \cup B \cup B \cup B \ldots \in \mathcal{A}$, se $\mathcal{A}$ é $\sigma$-álgebra.

Suponha que se admita que existam probabilidades em certa $\sigma$-álgebra $\mathcal{A}$ de eventos, e que a todo evento $A \in \mathcal{A}$ está associado um número real $P(A)$, a probabilidade do evento $A$, de modo que os seguintes axiomas sejam satisfeitos.

Axioma 1. $P(A) \geq 0$

Axioma 2. $P(\Omega)=1$

Axioma 3. Aditividade finita: Se $A_{1}, \ldots, A_{n} \in \mathcal{A}$, disjuntos 2 a 2, então $P\left(\cup_{i=1}^{n} A_{i}\right)=\sum_{i=1}^{n} P\left(A_{i}\right)$.

Axioma 3'. $\sigma$-Aditividade: Se $A_{1}, A_{2}, \ldots \in \mathcal{A}$, disjuntos 2 a 2, então $P\left(\cup_{n=1}^{\infty} A_{n}\right)=\sum_{n=1}^{\infty} P\left(A_{n}\right)$.

Temos que o Axioma A3' implica o Axioma 3, o que significa que se $P$ é $\sigma$ aditiva, então $P$ é finitamente aditiva.

Ao considerar no Exemplo 3.1.1, do mês de aniversário, em que todos os meses têm a mesma probabilidade $1 / 12$, sendo a $\sigma$-álgebra já estabelecida, os 
Axiomas 1 e 2 são satisfeitos? Deve-se considerar o axioma da aditividade finita ou infinita?

Definição 5. Uma função $P$, definida numa $\sigma$-álgebra $\&$ satisfazendo os Axiomas 1, 2 e 3', chama-se de medida de probabilidade em $\mathscr{A}$ ou simplesmente probabilidade em $\boldsymbol{A}$.

O espaço de probabilidade é constituído pelo trio $(\Omega, \mathcal{A}, P)$, em que $\Omega$ é o espaço amostral, $\mathcal{A}$ é a $\sigma$-álgebra de eventos aleatórios e $P$ é a probabilidade definida em $\not$.

Definição 6: Seja $(\Omega, \boldsymbol{A}, P)$ um espaço de probabilidade, $R$ o conjunto dos números reais e $\xi$ uma função real definida em $\Omega$ por:

$$
\begin{aligned}
\xi: \Omega & \rightarrow R \\
\omega & \rightarrow \xi(\omega),
\end{aligned}
$$

em que cada evento $\omega$ do espaço amostral tem um correspondente real $\xi(\omega)$. Dizemos que a função $\xi$ é uma variável aleatória, se para todo número $x \in R$, a relação a seguir for verificada.

$A=\{\omega \mid \xi(\omega) \leq x\} \in \mathscr{A}$, ou seja, verifica-se que $A$ é um evento, e mais, garante que a inversa $\xi^{-1}(\omega)$ seja um elemento do conjunto $\mathscr{A}$ ( $\sigma$-álgebra).

De forma bem intuitiva, podemos dizer que a variável aleatória é uma função definida sobre o espaço amostral $\Omega$, que atribui um valor real a cada elemento $\omega$ (ou evento elementar $\omega$ ) do espaço amostral.

Se o experimento simples é apenas sortear um aluno da sala $S$, então, como já foi dito, cada evento elementar será o próprio aluno e o espaço amostral, todos os alunos da sala. Considerando como variável $W$, o número de letras do primeiro nome do(a) aluno(a), por exemplo, se a aluna sorteada for Raissa, a ela se atribuirá o número $6, W$ (Raissa Santos) $=6$, se o aluno sorteado for Leonardo, $W$ (Leonardo Soares) $=8$.

Agora, se consideramos o número $x=4,5 \in R$, temos: $A=\{\omega$, que pertence ao conjunto dos alunos da sala $S / X(\omega) \leq x\}=\{\omega / W(\omega) \leq 4,5\}=$ $\{$ Ana Dantas, Ana Machado, Igor Silva, João Ramalho, Kaue Gomes $\} \in \mathcal{A}$.

Retomando o Exemplo 3.1.2, que se diferencia deste acima, porque além de sortear o aluno, registramos o número de letras do nome, temos que o espaço 
amostral pode ser definido por $\Omega_{1}=\{3,4,5,6,7,8,9,10\}$. Logo, neste caso, o elemento $\{3\}$ representa um evento elementar, enquanto que no exemplo anterior era o valor atribuído à variável $W$; se as alunas sorteadas fossem Ana Dantas ou Ana Machado, ou seja, $W($ Ana Dantas $)=3$ e $W($ Ana Machado $)=3$.

Considerando, agora, o espaço amostral $\Omega_{1}$, a variável aleatória $Y$ definida como a diferença entre o número 10 e o número de letras do primeiro nome, então, $Y$ atribuirá ao elemento 3 o número real 7. Logo pode-se construir a Tabela 12 para a variável aleatória $Y$.

Tabela 12: Tabela de valores para a variável aleatória $Y$

\begin{tabular}{l|l|l|l|l|l|l|l|l}
\hline$W$ & 3 & 4 & 5 & 6 & 7 & 8 & 9 & 10 \\
\hline$Y(w)$ & 7 & 6 & 5 & 4 & 3 & 2 & 1 & 0 \\
\hline
\end{tabular}

Agora, se consideramos o número $y=15 \in R$, então $A=\{\omega / X(\omega) \leq x\}=\{\omega /$ $Y(\omega) \leq 15\}=\Omega \in \mathcal{A}$. Se $y=3,5, B=\{\omega / Y(\omega) \leq 3\}=\{7,8,9,10\} \in \mathcal{A}$.

E quanto a probabilidade? As probabilidades são atribuídas a eventos, então, qual é a probabilidade que a variável $Y$ assume o valor 7 , ou seja, $P(Y=7)$ ? Temos que $P(Y=7)=P(Y(3)=7)=P(\{3\})=2 / 40$.

A distribuição de probabilidades da variável $Y$ é apresentada na Tabela 13

Tabela 13: Distribuição de probabilidades para variável aleatória $Y$

\begin{tabular}{l|l|l|l|l|l|l|l|l}
\hline$Y(w)$ & 0 & 1 & 2 & 3 & 4 & 5 & 6 & 7 \\
\hline$P(Y(w))$ & $1 / 40$ & $3 / 40$ & $6 / 40$ & $10 / 40$ & $8 / 40$ & $7 / 40$ & $3 / 40$ & $2 / 40$ \\
\hline
\end{tabular}

Podemos fazer operações com variáveis aleatórias. No exemplo de Galton, suponha que $\Omega_{3}=$ \{direito, esquerdo\}, e considere $X$, o número de bolas azuis que caem do lado direito; $Y$, o número de bolas azuis que caem do lado esquerdo, considerando o prego colocado no meio (eventos equiprováveis).

A partir das variáveis aleatórias $X$ e $Y$, podemos gerar a variável aleatória $Z$ que é a diferença entre o número de bolas azuis que caem do lado esquerdo com as que caem do lado direito, ou seja, $Z=X-Y$. Sobre a suposição teórica de equiprobabilidade é correto pensar que o único valor assumido para a variável $Z$ seria $Z=0$, com probabilidade 1 ? Mas isto na realidade é possível? $Z$ poderia assumir outros valores? Como podem ser atribuídas as probabilidades a cada um destes? 
É muito comum confundir variável aleatória com espaço amostral, e uma maneira de esclarecer esta diferença é destacar que, em alguns casos, podemos observar que, a partir de um mesmo experimento, podemos definir distintas variáveis aleatórias. Retomando os exemplos apresentados na seção anterior, para a população de alunos - todos os alunos da turma $S$ - do Exemplo 3.1.1, podemos considerar a variável aleatória $X$, tal que vale 1 , se o mês em que o aluno sorteado faz aniversário começa com a letra $J$ e, zero, caso contrário. Como três meses iniciam com a letra $J$, e, sabendo que no sorteio ao acaso, todos os alunos tem a mesma probabilidade de serem sorteados, temos que a $P(X=1)=11 / 40$ e $P(X=0)=29 / 40$. Considere agora a variável aleatória $Y$, que vale 1 , se o mês em que fez aniversário é de verão e, zero, caso contrário. No hemisfério sul estes meses são dezembro, janeiro, fevereiro e março assim a $P(Y=1)=8 / 40$, e $P(Y=0)=32 / 40$.

Seja agora a variável $Z$ definida como $Z=X+Y$, então $Z$ pode assumir o valor 2 se 0 aluno sorteado nasceu em Janeiro $(X=1$ e $Y=1)$, o valor 1 se o aluno sorteado faz aniversário em fevereiro, março, junho, julho ou dezembro ( $X=1$ e $Y=0$ ou $X=0$ e $Y=1$ ), zero, se faz aniversário nos meses abril, maio, agosto, setembro, outubro, novembro $(X=0$ e $Y=0)$. Utilizando os resultados da Tabela 2 temos que

$$
P(Z=2)=2 / 40, P(Z=1)=15 / 40 \text { e } P(Z=0)=23 / 40 .
$$

Consideremos o experimento sortear um aluno da sala $S$, lembrando mais uma vez que neste caso o espaço amostral é todos os alunos da sala, e vamos definir mais duas variáveis: $K$ é o número de letras do último sobrenome do aluno sorteado e a variável $T$ representa a diferença entre o número de letras do primeiro nome $(W)$ e o número de letras do último sobrenome $(K)$ (reforçando que as variáveis devem estar no mesmo espaço amostral).

Então a variável $T$ pode assumir um dos valores do conjunto $\{-4,-3,-2,-1,0$, $1,2,3,4\}$ e as frequências de ocorrências desses valores são apresentadas na Tabela 14.

Tabela 14: Frequência da variável $T$, diferença entre o número de letras do primeiro nome $(W)$ e o número de letras do último sobrenome $(K)$.

\begin{tabular}{c|cccccccccc}
\hline \multicolumn{1}{c|}{$t$} & -4 & -3 & -2 & -1 & 0 & 1 & 2 & 3 & 4 & Total \\
\hline $\begin{array}{l}\text { Quantidade de alunos } \\
\text { que possui diferença } t\end{array}$ & 1 & 3 & 5 & 4 & 9 & 7 & 6 & 4 & 1 & 40 \\
\hline Frequência relativa & $1 / 40$ & $3 / 40$ & $5 / 40$ & $4 / 40$ & $9 / 40$ & $7 / 40$ & $6 / 40$ & $4 / 40$ & $1 / 40$ & 1 \\
\hline
\end{tabular}


Assim, por exemplo, se deseja-se saber qual é a probabilidade da variável aleatória $T=-2$, ou seja, $P(T=-2)$, pela Tabela 14 , temos que $P(T=-2)=5 / 40$.

O professor pode perguntar aos alunos, qual é probabilidade de $T$ ser igual a 3, que poderá ser respondido usando os resultados da Tabela 14. Pode-se, ainda, sugerir que os alunos criem novas variáveis aleatórias, tendo definido claramente o espaço amostral e a forma de atribuição de probabilidades. Além disso o professor pode motivar a que os alunos realizem operações entre elas e se possível atribua um significado prático.

Com os exemplos apresentados até o momento, tentamos esclarecer ao leitor, partindo de uma abordagem intuitiva, até chegar à apresentação mais formal do conceito de variável aleatória. Isso, segundo os preceitos de Heitele (1975), abordando o tema por meio de várias representações e com profundidades distintas.

O ensino de estatística na educação básica, no geral, é superficial e com poucas discussões e exemplos que não estejam associados a jogos de azar. Parte deste problema foi discutida no início deste trabalho, quando apontamos o fato de estatística inicialmente ter sido tratada como tratamento da informação sem ter uma área específica. Espera-se que com a implementação da BNCC, e tendo um bloco específico para Estatística e Probabilidade, este panorama se altere.

\subsection{Abordagem de variáveis aleatórias no ensino superior}

Pensando na possível dificuldade do professor ao associar o ensino de estatística com variáveis aleatórias no Ensino Fundamental, decidimos comentar, de forma sucinta, as abordagens deste assunto em alguns livros de estatística, que costumam ser utilizados no Ensino Superior. Consideramos dois dos quatro livros que constam na bibliografia da disciplina "Estatística para Licenciatura I" oferecida no curso de licenciatura em Matemática do Instituto de Matemática e Estatística da Universidade de São Paulo (IME-USP), são eles: Noções de Probabilidade e Estatística (Magalhães e Lima, 2015) e Estatística Básica (Bussab e Morettin, 2017).

No livro Noções de Probabilidade e Estatística, os autores apresentam variáveis estatísticas antes de apresentar variáveis aleatórias. Alguns conceitos fundamentais são definidos antes de abordar variáveis aleatórias. O primeiro deles é referente ao experimento aleatório. Magalhães e Lima (2015) definem na página 37 
fenômenos aleatórios como sendo "situação ou acontecimentos que não podem ser previstos com certeza".

As próximas definições que os autores abordam são de espaço amostral, evento e, em seguida, apresentam a função probabilidade $P($.$) na página 38$, como uma "função que atribui valores numéricos aos eventos do espaço amostral", seguida de sua definição teórica como apresentado a seguir.

Uma função $P(\cdot)$ é denominada probabilidade se satisfaz as condições:

i) $\quad 0 \leq P(A) \leq 1, \forall A \subset \Omega$;

ii) $\quad P(\Omega)=1$;

iii) $\quad P\left(\cup_{j=1}^{n} A_{j}\right)=\sum_{j=1}^{n} P\left(A_{j}\right)$, com os $A_{j}$ disjuntos.

Um aspecto importante a ser destacado é o de não apresentar a definição formal de variáveis aleatórias (utilizando explicitamente funções). É mencionada a expressão "associada" para apresentar a ideia de função. De maneira positiva, o livro conta com diversos exemplos que fogem dos problemas de jogos de azar e dados, inclusive apontando a aplicabilidade para outras áreas. $O$ professor pode inclusive utilizar os exemplos apresentados neste livro como exercícios e situações para seus alunos, o que seria muito enriquecedor para aulas, uma vez que foge dos exemplos envolvendo dados, moedas e baralhos.

Dois processadores tipos $A$ e $B$ são colocados em teste por 50 mil horas. A probabilidade de que um erro de cálculo aconteça em um processador do tipo $A$ é de $1 / 30$, no tipo $B, 1 / 80$ e, em ambos 1/1000. (MAGALHÃES; LIMA, 2015)

Como sugestão, o professor poderá utilizar situações como a explicitada descrita anteriormente para explorar o assunto de maneira mais aplicada.

Após a definição da função probabilidade, o livro destaca um capítulo para variáveis aleatórias discretas e propõe uma ligação com as variáveis estatísticas, quando faz menção ao Capítulo 1. Apresenta também a classificação de variáveis aleatórias, como pode ser observado no parágrafo a seguir.

Neste capítulo, incorporamos o conceito de probabilidade no estudo de variáveis associadas a características em uma população. No Capítulo 1 , vimos que, utilizando uma tabela de frequência, podemos apresentar os valores possíveis para uma dada variável e suas respectivas frequências. (...) Uma quantidade $X$, associada a cada possível resultado do espaço amostral é denominada de variável aleatória discreta, se assume valores num conjunto enumerável, com certa probabilidade. Por outro lado, será 
denominada variável aleatória contínua, se seu conjunto de valores é qualquer intervalo dos números reais. (MAGALHÃES; LIMA, 2015, p57)

Neste trabalho definimos variável aleatória após ter trabalhado a noção de experimento aleatório, tentando relacionar com variáveis estatísticas simples associadas. Em alguns trabalhos (RIOS, 1967 apud RUIZ; BATANERO, ARTEAGA, 2011) é apresentado o conceito de variável aleatória a partir das variáveis estatísticas.

Em Magalhães e Lima (2015), assim como Rios, define-se variável aleatória como uma extensão de variável estatística, atribuindo-se funções de probabilidade, continuando com a especificação de algumas distribuições discretas e contínuas.

Primeiro Rios (1967, apud RUIZ; BATANERO, ARTEAGA, 2011) define variável estatística, como sendo a variável que representa os $n$ resultados de $n$ experimentos (ou repetições) de certo experimento aleatório.

Se considerarmos um experimento aleatório $S$ e realizarmos um certo número $n$ de experimentos relativos ao mesmo, obtemos um conjunto de observações, que se chama amostra aleatória de tamanho $n$. Este conjunto de resultados dará lugar a uma tabela estatística em que a um certo valor da variável corresponde uma certa frequência. Essa variável, que representa unicamente os $n$ resultados de $n$ realizações do experimento aleatório S, denominaremos variável estatística. (RIOS, 1967, p. 70, apud RUIZ; BATANERO, ARTEAGA, 2011, tradução livre da autora).

Em seguida, apresenta a definição de variável aleatória, como segue:

Se imaginarmos realizada uma infinidade de experimentos relativos ao experimento $S$, a infinidade de resultados possíveis origina a noção de variável aleatória associada ao experimento $S$. Neste caso a variável aleatória assume os valores que representam os eventos elementares possíveis deste experimento com uma certa probabilidade que a corresponde. (RIOS, 1967, p. 70, apud RUIZ; BATANERO, ARTEAGA, 2011, tradução livre da autora).

O conceito de variável estatística está amplamente ligado ao conceito de variável aleatória e no livro de Magalhães e Lima esta relação está bem clara. Notando que a diferença está que, em Rios, variável aleatória está associada à definição frequentista de probabilidade, restrição não observada no livro de Magalhães e Lima. Entretanto, pode resultar motivador ao professor basear-se na noção frequentista ao trabalhar com dados resultantes de amostragem, como é o caso dos dados apresentados pelo IBGE.

De forma próxima a este trabalho, o livro Estatística Básica, inicialmente é apresentado ao leitor um exemplo e em seguida propõe a construção de um espaço amostral, para então definir o conceito de variável aleatória. 
Um fato interessante é que esse livro realiza a representação por meio de diagramas e exemplos para facilitar a compreensão de variável aleatória, para, por fim, formalizar o conceito.

No capítulo em que Bussab e Morettin dão início à explicação de variáveis aleatórias discretas, os autores optaram por iniciar o capítulo com um exemplo:

Um empresário pretende estabelecer uma firma para montagem de um produto composto de uma esfera e um cilindro. As partes são adquiridas em fábricas diferentes $(A$ e $B)$, e a montagem consistirá em juntar as duas partes e pintá-las. O produto acabado deve ter o comprimento (definido pelo cilindro) e a espessura (definida pela esfera) dentro de certos limites, e isso só poderá ser verificado após a montagem. Para estudar a viabilidade de seu empreendimento, o empresário quer ter uma ideia da distribuição do lucro por peça montada. (BUSSAB; MORETTIN, 2017)

Vale ressaltar que o exemplo também enfatiza uma aplicação prática e, por meio desta situação, os autores apresentam várias variáveis aleatórias, como por exemplo, o lucro de cada conjunto (esfera cilindro) e o custo de recuperação de cada conjunto produzido. Bussab e Morettin (2017) definem variável aleatória discreta na página 134 como "uma função $X$, definida no espaço amostral $\Omega$ e que assume valores em um conjunto enumerável de pontos da reta".

Após a definição de variáveis aleatórias discretas, os autores apresentam a função de probabilidade de uma variável aleatória discreta e suas distribuições. Um próximo capítulo é dedicado para as variáveis aleatórias contínuas.

Nosso trabalho aproxima-se da forma como Morettin e Bussab apresentam a definição de variáveis aleatórias em seu livro. Iniciando com um exemplo, define-se variável aleatória e depois tratam da distribuição de probabilidades.

A vantagem da apresentação de variáveis aleatórias como Morettin e Bussab abordam é que parece ser mais natural: ela parte de noções intuitivas, fazendo inclusive o uso de representações esquemáticas. Pensando em um aluno de licenciatura em matemática, por exemplo, que costuma ter estatística nos primeiros anos de graduação e, tendo em vista que muitos dos ingressantes não tiveram estatística no ensino médio e, se tiveram, foi de forma superficial, uma abordagem em espiral, partindo de exemplos intuitivos pode auxiliar na compreensão dos conceitos e facilitar a aprendizagem. Além disso, pode inspirar o futuro docente a fazer uso de exemplos e atividades que possam facilitar a definição intuitiva, para 
depois formalizar os conceitos com seus alunos, isto é, passar a um fazer mais analítico. 


\section{Considerações finais}

Iniciamos este trabalho tentando responder se era possível na abordagem de estatística na educação básica, a ideia fundamental de variável aleatória. Para isso, iniciou-se um longo processo de investigação, busca de artigos, teses de doutorados tanto em nível nacional quanto internacional. A primeira observação notada é que na literatura brasileira existiam poucas pesquisas acerca deste assunto e isso motivou ainda mais seguir neste tema, pois pode ser de grande contribuição na formação do professor.

Realizado o levantamento bibliográfico, optou-se por iniciar o trabalho apresentando um breve panorama do ensino de estatística no Brasil e, também, apresentar ligações com o contexto internacional. No Brasil, de acordo com os PCNs, estatística era apresentada aos alunos no bloco tratamento de informações e tinha como proposta a relação com os temas transversais. Com a promulgação da BNCC, estatística, no ensino fundamental, ganha um bloco especial - Estatística e Probabilidade - que deve ser trabalhado com os alunos desde os anos iniciais, o qual representa um grande desafio hoje para os professores de matemática.

Alguns documentos internacionais, como o GAISE e o NCTM inspiraram a elaboração dos nossos exemplos de atividades, pois estes possuem uma ampla gama de sugestões e exemplos.

Com o intuito de fazer o uso de uma apresentação em espiral, o Capítulo 3 foi dividido em duas sessões, a primeira foi direcionada aos exemplos, porém não foi deixado de apresentar conceitos como experimento aleatório, evento, espaço amostral, variável aleatória, censo, amostra, mesmo que de maneira intuitiva, e dedicamos a segunda parte do capítulo, para sistematizar todos os conceitos vistos anteriormente, mas com uma profundidade maior. Apesar de alguns assuntos do Capítulo 4 não serem abordados no ensino fundamental, acreditamos que possam servir como aporte teórico ao professor leitor deste trabalho.

As ideias fundamentais de Heitele (1975) para o ensino de estatística, entre elas variáveis aleatórias, nortearam todos os exemplos mencionados e ressaltando, em todos os casos, a diferença entre variáveis aleatórias e espaço amostral. Recorrendo aos exemplos dados ao longo do trabalho, foi possível deixar clara esta distinção, o que acreditamos que seja um ponto positivo para este trabalho, uma vez que esta confusão é recorrente, inclusive em alunos de graduação. 
Tendo em vista a dificuldade em entender o conceito de variáveis aleatórias, optamos por realizar uma análise de como este assunto está abordado nos livros destinados a graduação, analisando as principais características de cada um deles, sendo ambos muito recomendados.

Para finalizar, acreditamos que as atividades propostas neste trabalho, com a inclusão de perguntas abertas, podem servir de motivação para que o professor de matemática, que já estudou de maneira formal ou analítica o conceito de variável, possa refletir sua prática docente. Por outro lado, esperamos também que a leitura deste texto, com formalização dos conceitos apresentados, possa contribuir para completar a formação do professor, que não teve a oportunidade de se aprofundar nesta ideia fundamental da estatística. 


\section{Referências Bibliográficas}

ALBERT, A.; RUIZ, B. Didáctica de la probabilidad y estadística el caso de la variable aleatoria. 2005

BARON, M.; BOS, H. Curso de história da matemática: origens e desenvolvimento do cálculo. UnB., 1985.

BARROS, D. et al. Determinação da taxa de ocupação de ambientes internos fechados em função da potência de sinal recebido em redes de sensores sem fio. 2014

BATANERO, C. Dificultades de los estudiantes en los conceptos estadísticos elementales: el caso de las medidas de posición central. Ensino e aprendizagem da estatística, p. 31-48, 2000.

BATANERO, C.; GODINO, J. Stochastics and its didactics for teachers: EdumatTeachers project. Granada, Universidad de Granada, 2002.

BRASIL, Parâmetros Curriculares Nacionais. Matemática. Brasília: Ministério da Educação/Secretaria de Educação Fundamental, 1997.

BRASIL, Parâmetros Curriculares Nacionais. Matemática. Brasília: Ministério da Educação/Secretaria de Educação Fundamental, 1998.

BRASIL, Mistério da Educação. Base Nacional Comum Curricular. Brasília-DF: MEC, Secretaria de Educação Básica, 2017.

BRUNER, J. O processo da educação. 3. ed. São Paulo: Companhia Editora Nacional, 1973.

CAZORLA, I. et al. A relação entre a habilidade viso-pictórica e o domínio de conceitos estatísticos na leitura de gráficos. 2002. 
FRANKLIN, C. et al. Guidelines for assessment and instruction in statistics education (GAISE) report. Alexandria: American Statistical Association, 2007.

GUIMARÃES, G. et al. A educação estatística na educação infantil e nos anos iniciais. Zetetike, v. 17, n. 2, 2009.

HEITELE, D. An epistemological view on fundamental stochastic ideas. Educational studies in Mathematics, v. 6, n. 2, p. 187-205, 1975.

LOPES, C.E; CARVALHO, C. Educação matemática e educação estatística: intersecções na produção científica. Ensino de Ciências e Matemática: Tópicos em Ensino e Pesquisa. São Paulo: ANDROSS, p. 177-196, 2006.

LOPES, C.E. O ensino da estatística e da probabilidade na educação básica e a formação dos professores. Cad. Cedes, Campinas, v. 28, n. 74, p. 57-73, 2008.

NOVAES, D.V. et al. Concepções de professores da Educação Básica sobre variabilidade estatística. VI Coloquio Internacional Enseñanza de las Matemáticas, p. 50, 2011.

OLIVEIRA, M. B. Probabilidade e estatística .1ª ed. Itaperuna, RJ: Begni, 2012

PANAINO, R. Estatística no Ensino Fundamental: uma proposta de inclusão de conteúdos matemáticos. Rio Claro - SP: Instituto de Geociências e Ciências Exatas. Dissertação de Mestrado, UNESP, Rio Claro-SP, 1998

PIZZANI, Luciana et al. A arte da pesquisa bibliográfica na busca do conhecimento. RDBCl: Revista Digital de Biblioteconomia e Ciência da Informação, v. 10, n. 2, p. 53-66, 2012.

RUIZ, B. Análisis epistemológico de la variable aleatoria y comprensión de objetos matemáticos relacionados por estudiantes universitarios. 2013. Tese de Doutorado. Universidad de Granada. 
RUIZ, B.; BATANERO, C.; ARTEAGA, P. Vinculando a variável aleatória e estatísticas na realização de inferências informais por futuros professores. Bolema - Boletim de Educação Matemática, v. 24, n. 39, p. 431449, 2011.

SEVERINO, Antônio Joaquim. Metodologia do trabalho científico. Cortez editora, 2017.

WALICHINSKI, D.; DOS SANTOS JUNIOR, G.; ISHIKAWA, E.C.M. Educação estatística e parâmetros curriculares nacionais: algumas considerações. Revista Brasileira de Ensino de Ciência e Tecnologia, v. 7, n. 3, 2014. 